\title{
Assessment of the Performances of RANS Models for Simulating Swirling Flows in a Can-Combustor
}

\author{
K. Khademi Shamami and M. Birouk ${ }^{*}$
}

\author{
Department of Mechanical and Manufacturing Engineering, the University of Manitoba, Winnipeg, Manitoba, R3T 5V6, \\ Canada
}

\begin{abstract}
The paper presents an assessment of the performances of RANS turbulence models for simulating turbulent swirling can-combustor flows with different inlet swirl intensities (i.e. $S=0.4$ and $S=0.81$ ). The predictions compared against published experimental data reveal that the eddy-viscosity models can not show the central recirculation zone in the case of a weakly swirling flow. However, although they reveal the existence of this region in a strongly swirling flow, they are incapable of predicting its correct size. On the other hand, the Reynolds stress models are able to predict the corner and the central recirculation zones in both flow cases. The predictions of turbulence intensities by using the realizable $k-\varepsilon$ and the SST $k-\omega$ are comparable to those of the Reynolds stress closures. The shear stresses are not well predicted by all the tested models. Both the eddy-viscosity and the Reynolds stress closures show relatively less approximation errors in the weakly swirling flow.
\end{abstract}

\section{INTRODUCTION}

Swirling flows are used in a wide variety of engineering applications, such as furnaces and gas turbine combustors. The use of swirl in these power systems has several benefits. It is recognized that a swirling flow produces an adverse pressure gradient that can cause flow reversal or vortex breakdown. The swirling flow's central recirculation zone may result in decreasing pollutants emission by bringing hot species back to the combustion zone as well as lowering the possibility of flame blow-off. Moreover, swirl causes further mixing between the fuel and the oxidant.

To improve the performance of a combustor, an accurate insight into the flow structure is needed. Due to the complex turbulent nature of a swirling flow in a combustor, accurate numerical calculations of the flow parameters require a careful choice of turbulence models. These models are needed to calculate the turbulent stress terms in the mathematical equations that describe the flow dynamics. A review of the literature reveals that numerous studies are reported on the mathematical calculations of swirling flows in a combustor. It is shown that the standard $k-\varepsilon$ model [1-2] and its different versions (e.g. References [3-5]) which can perform reasonably well for simulating simple turbulent flows, appear inadequate for simulating swirling flows [6-28]. Using different versions of the $k-\varepsilon$ turbulence model, Hogg et al. [6], Jones et al. [7], Sharif et al. [8], Chen et al. [9], Yaras et al. [10], and Yang et al. [11], carried out numerical simulation of a highly swirling flow $(S=2.25)$ in a cylindrical combustor measured by So et al. [29]. It is reported that the $k-\varepsilon$ model exhibits an excessive level of turbulent diffusion and its predictions for the mean flowfield of the studied case [29] are not satisfactory. The deficiency of the $k-\varepsilon$ model in

*Address correspondence to this author at the Department of Mechanical and Manufacturing Engineering, The University of Manitoba, Winnipeg, Manitoba R3T 5V6, Canada; E-mail: biroukm@cc.umanitoba.ca predicting the turbulent diffusion is recognized in the simulation of other swirling flows in different combustor geometries and in a wide range of swirl numbers [12-28,30]. For example, Tsao et al. [28] simulate a can-type gas turbine combustor for two swirl numbers $(S=0.74$, and 0.85$)$ and show that the $k-\varepsilon$ model predicts a relatively higher level of deceleration of the axial velocity in the centerline region of the combustor which is a sign of excessive diffusion and hence higher level of swirl entrainment. However, later versions of the $k-\varepsilon$ model show improvement over the standard $k-\varepsilon$ model in predicting the characteristics of swirling flows but still less accurate as compared to experimental data [16,19,26,31-34]. The persistent deficiency of these models is believed to be a result of their use of isotropic eddyviscosity concept, while the structure of turbulent swirling flows is mostly anisotropic [35]. In addition, the eddyviscosity models have difficulties in accounting properly for turbulence-swirl interactions. For instance, the $R N G k-\varepsilon$ model [36] is employed to simulate several configurations of confined swirling flows $[16,19,37]$. Recall that the $R N G k-\varepsilon$ and the standard $k-\varepsilon$ differ mainly in the expression of the dissipation $(\varepsilon)$ equation. In the $R N G k-\varepsilon$ model a new term is introduced into the dissipation $(\varepsilon)$ equation which results in an apparent success of this version of $k-\varepsilon$ models in predicting the length of recirculation zones of several separating flows [37-39]. However, in some cases predictions of the $R N G k-\varepsilon$ and the $k-\varepsilon$ are not much different. For example, Xia et al. [19] examine both the standard $k-\varepsilon$ and the $R N G k$ $\varepsilon$ models for predicting a strongly swirling flow $(S=1.68)$ in a water model combustion chamber, and find that both of the models give fairly accurate results near the inlet region but fail to reproduce accurately the downstream flow characteristics, although the $R N G k-\varepsilon$ model is found to make a slightly improved predictions near the flow inlet. A major weakness of the standard $k-\varepsilon$ model or other traditional $k-\varepsilon$ models, such as $R N G k-\varepsilon$ model, lies in their way of modeling the dissipation $(\varepsilon)$ equation. The realizable $k-\varepsilon$ model [40] is intended to address the deficiencies of these $k$ - $\varepsilon$ models by 
introducing a new eddy-viscosity formula and a new dissipation equation that is based on the dynamic equation of the mean-square vorticity fluctuation [40-41]. Zhu et al. [16] employ the standard $k-\varepsilon$, the $R N G k-\varepsilon$, and the realizable $k-\varepsilon$ model in the simulation of coflow jets in a cylindrical combustor. They find that the realizable $k-\varepsilon$ model works better than does the standard $k-\varepsilon$ model, while the $R N G k-\varepsilon$ model does not give improvements over the standard $k-\varepsilon$ model. In the shear-stress transport (SST) $k$ - $\omega$ model [42], the definition of the turbulent viscosity is re-defined along with the addition of a cross-diffusion term in the $\omega$-equation. These modifications of the SST $k$ - $\omega$ model show better performance over both the standard $k-\varepsilon$ and $R N G k-\varepsilon$ models [41-42]. Nonetheless, it is reported that the SST $k$ - $\omega$ model yields excessive radial diffusive transport in both upstream and downstream of a strongly swirling flow [10]. Engdar et al. [21] investigate the performance of the standard $k-\varepsilon$ model and the SST $k-\omega$ model in the simulation of a confined swirling flow. They find that in a swirling flow with $S=0.58$, the standard $k-\varepsilon$ model is not able to predict the central recirculation zone, while the SST $k$ - $\omega$ model shows this regignther turbulence closure models, such as algebraic Reynolds stress model $(A S M)$, are used for simulating swirling turbulent flows $[8,13,20,25,43-46]$. It is shown [44-45] that the $A S M$ is not able to simulate properly axisymmetric swirling flows, because of significant stress transport processes present in this type of flows. However, new modified versions of the $A S M$ are employed to simulate several swirling flow configurations $[13,20,25,45-46]$, which appear to produce better predictions over the standard $k-\varepsilon$ model. Zhang et al. [46] simulate a confined coaxial swirling jet using a new $A S M$ and compare their results with those obtained via the $k$ $\varepsilon$ model. They report that the mean and fluctuating velocities predicted by the $A S M$ are superior to those of the $k-\varepsilon$ model. The $k-\varepsilon$ is reported to be incapable of showing the central reverse flow, while the $A S M$ reveals the existence of this region [46].

The standard Reynolds stress model (RSM) [47], and its different versions are also tested for several swirling flow configurations and satisfactory predictions are achieved [6$9,13,17-19,23,28,48-53]$. However, the RSM model is found incapable of resolving all the deficiencies of the twoequation models for simulating turbulent swirling flows [78,17-18,48-50,54-56]. For example, Tsai et al. [18] find that for a weakly swirling flow $(S=0.3)$ the $k-\varepsilon$ model predicts a faster axial velocity recovery, while the $R S M$ model yields a relatively slow axial velocity development, though the stress closure $(R S M)$ performs better in general. It is also reported that the intensity of turbulence is underpredicted by the stress model along the centerline [18,49-50]. Hanjalic $[39,57]$ report that both the equations for the dissipation rate of $k$ and the pressure-strain term are the main source of inaccuracy in predicting turbulence quantities. Modified versions of the RSM are proposed [50,58-59]. For example, Lumley et al. [58] model the source term of the transport $\varepsilon$-equation in a new way. However, their work is not very helpful in simulating complex swirling flows [50]. Speziale et al. [59] propose a new quadratic model for the pressure-strain term (SSG) which appears to produce accurate results of various types of flows [9,50-51,60-61]. For example, Chen et al. [9] employ the $S S G$ model in simulating confined swirling flows $(S=0.85$, and 2.25) and report that the $S S G$ model predicts the flow adequately in both of the cases. Lu et al. [50] introduce a modified source term of the transport $\varepsilon$-equation based on physical reasoning in that anisotropy is responsible for the turbulent transfer from large- to small-scale eddies in regions of predominantly anisotropic turbulence, and that isotropy controls the turbulent kinetic energy transfer in flow regions where turbulence is predominantly isotropic. They find that their new $\varepsilon$-equation together with the $S S G$ model exhibits a strong improvement in the prediction of a weakly $(S=0.5)$ swirling flow. It is also reported that the $S S G$ model performs well in the vicinity of a wall, in spite of the fact that its formulation does not contain wall-reflection correction terms [50].

The literature reviewed above show that confined swirling flows are studied experimentally and numerically. Mainly, the confinement is either a dump (can) combustor or a straight pipe (cylinder). It is demonstrated experimentally that the inlet swirl intensity can alter significantly the swirling flow field characteristics. It can, for example, drastically change the position and size of different regions of the flow, e.g. the central toroidal recirculation zone (CTRZ) and the corner recirculation zone (CRZ) [11-12,17,62-66]. In a dump combustor, the CRZ always exists, whereas the CTRZ may not occur at low inlet swirl intensities. On the other hand, in a straight pipe (cylinder), the CRZ does not exist; however, the CTRZ may occur at high swirl intensities. Therefore, both the inlet swirl intensity and type of confinement geometry have an impact on the overall characteristics of a swirling flowfield. It has also been shown that the swirler design (inlet velocity profile) can change the flowfield of a combustor [62]. Although there are numerous studies in which some of RANS models are employed to simulate swirling flows with different inlet swirl intensities (e.g. Ref [50]: $S=0.5, S=2.25$ ), a comprehensive parametric study that enables to examining the performance of these numerical models appears to be lacking. For example, two different geometries (i.e. a straight pipe and a dump combustor) have been used in Ref [50], but for each geometry only one single inlet swirl intensity is tested. In addition, the swirler design (inlet swirling flow profile) is also different in both geometries. For instance, the corner recirculation zone does exist only in the dump combustor geometry. Moreover, in some other numerical works (such as Ref [14]) although it is claimed that only the inlet swirl intensity is varied, the literature show that either the inlet swirl intensity range is not wide enough to alter the main features of the flow field or there is a lack of comprehensive comparative examinations of the performance of different RANS models. Another issue that arises while reviewing the literature is the fact that some of the twoequation models (i.e. $R N G k$ - $\varepsilon$, realizable $k-\varepsilon$, and SST $k$ - $\omega$ ) have been rarely tested in predicting the mean and turbulence quantities of swirling flows in a can-combustor with different inlet swirl numbers.

Therefore, the present study attempts to provide a comprehensive parametric analysis of the performance of the most recognized RANS turbulence models for predicting the 
main characteristics of a can-combustor swirling flow with different inlet swirl intensities (i.e. $S=0.4$ and $S=0.81$ ). In contrast to previous studies, in the present work only the swirl intensity is varied, as both the swirler design and combustor geometry are kept the same. Therefore, only the inlet swirl intensity affects the numerical predictions of different models for the two flow cases. The adopted two inlet swirl intensities are thought to be representative of the weak and strong swirling flow characteristics. Also, it is important to note that the choice of this particular geometry is driven by the fact that the experimental data are readily available for various inlet swirl numbers $[63,67]$, and also due to its industrial pertinence. The turbulence models to be tested are grouped into two families: ( $i$ ) the two-equation eddyviscosity models, which are the $k-\varepsilon, R N G k-\varepsilon$, realizable $k-\varepsilon$, and the SST k- $\omega$, and (ii) the Reynolds stress models, which are the standard $R S M$ and the $S S G$.

\section{COMPUTATIONAL DETAILS}

\subsection{Governing Equations}

The mass and momentum Reynolds-averaged equations for a turbulent steady-state flow can be written in tensor notation as follows:

$$
\begin{aligned}
& \frac{\partial\left(\rho U_{i}\right)}{\partial x_{i}}=0 \\
& \frac{\partial\left(\rho U_{i} U_{j}\right)}{\partial x_{j}}=-\frac{\partial P}{\partial x_{i}}+\frac{\partial}{\partial x_{i}}\left(\mu \frac{\partial U_{i}}{\partial x_{j}}-\rho \overline{u_{i} u_{j}}\right)
\end{aligned}
$$

In equation (2) the time-averaged value of the velocity fluctuating tensors, $\overline{u_{i} u_{j}}$, are unknown. They are generally identified as Reynolds stresses.

\subsection{TURBULENCE MODELS}

The numerical solution of equations (1) and (2) for a turbulent flow can be obtained only by introducing additional equations for the Reynolds stresses. These equations contain other correlations of higher order which have to be modeled in order to close the system of Reynolds-averaged equations (e.g. Eq. (2)). The turbulence closure models employed in the present work are summarized briefly below.

\section{$k-\varepsilon$ Model}

In the $k-\varepsilon$ model, the Reynolds stresses are linearly related to the mean rate of strain by a scalar eddy viscosity as follows [68]:

$-\rho \overline{u_{i} u_{j}}=2 \mu_{t} S_{i j}-\frac{2}{3} \rho k \delta_{i j}$

where $S_{i j}$ and $\mu_{t}$ are the mean rate of strain tensor and the eddy viscosity which are given, respectively, as

$$
\begin{aligned}
& S_{i j}=\frac{1}{2}\left(\frac{\partial U_{i}}{\partial x_{j}}+\frac{\partial U_{j}}{\partial x_{i}}\right) \\
& \mu_{t}=C_{\mu} \rho \frac{k^{2}}{\varepsilon}
\end{aligned}
$$

where $k$ and $\varepsilon$ are the turbulent kinetic energy and dissipation rate, respectively, which are expressed as

$k=\frac{1}{2} \overline{u_{i} u_{i}}$

$\varepsilon=v \overline{\frac{\partial u_{i}}{\partial x_{j}} \frac{\partial u_{i}}{\partial x_{j}}}$

The $k-\varepsilon$ model (called KEM in the present study), consists of the following transport equations for $k$ and $\varepsilon$

$$
\begin{aligned}
\frac{\partial\left(\rho U_{j} k\right)}{\partial x_{j}}= & \frac{\partial}{\partial x_{j}}\left(\left(\mu+\frac{\mu_{t}}{\sigma_{k}}\right) \frac{\partial k}{\partial x_{j}}\right)+2 \mu_{t} S_{i j} S_{i j}-\rho \varepsilon \\
\frac{\partial\left(\rho U_{j} \varepsilon\right)}{\partial x_{j}}= & \frac{\partial}{\partial x_{j}}\left(\left(\mu+\frac{\mu_{t}}{\sigma_{\varepsilon}}\right) \frac{\partial \varepsilon}{\partial x_{j}}\right) \\
& +2 C_{1 \varepsilon} \frac{\varepsilon}{k} \mu_{t} S_{i j} S_{i j}-C_{2 \varepsilon} \rho \frac{\varepsilon^{2}}{k}
\end{aligned}
$$

The model constants, which are summarized in Table 1, are determined from experiments for homogeneous shear flows and isotropic grid turbulence [1].

\section{RNG $\boldsymbol{k}-\varepsilon$ Model}

The $R N G$-based $k$ - $\varepsilon$ model (called $R N G$ in the present study), is derived by using a mathematical technique called "renormalization group" $(R N G)$ method [69]. It has a similar form to the KEM. The model constants, which are summarized in Table 1, are obtained analytically [36]. It is shown [41] that in regions of weak and moderate strain rate, the $R N G$ model yields results comparable to the standard $k-\varepsilon$ model. On the other hand, in regions of large strain rate the $R N G$ model shows a lower turbulent viscosity than the standard $k-\varepsilon$ model. Therefore, the $R N G$ model is more responsive to the effects of rapid strain and streamline curvature than the standard $k-\varepsilon$ model [41]. A more comprehensive description of the $R N G$ can be found in $[41,70]$.

Table 1. The $k-\varepsilon$ Based Models Coefficients

\begin{tabular}{|c|c|c|c|c|c|}
\hline & $\mathbf{C}_{\boldsymbol{\mu}}$ & $\mathbf{C}_{1 \varepsilon}$ & $\mathbf{C}_{2 \varepsilon}$ & $\boldsymbol{\sigma}_{\mathbf{k}}$ & $\boldsymbol{\sigma}_{\varepsilon}$ \\
\hline \hline KEM & 0.09 & 1.44 & 1.92 & 1 & 1.3 \\
\hline RNG & 0.0845 & 1.42 & 1.68 & 0.7179 & 0.7179 \\
\hline RKEM & - & 1.44 & 1.9 & 1 & 1.2 \\
\hline
\end{tabular}

\section{Realizable k-E Model}

The realizable $k-\varepsilon$ model (called RKEM in the present study), which is proposed by Shih et al. [40] has a new eddy viscosity equation with a variable $C_{\mu}$, as well as a new dissipation equation. The $k$-equation in the RKEM model has the same form as that in the KEM and $R N G$ models; however, the $\varepsilon$-equation is different. In contrast to the standard $k-\varepsilon$ and the $R N G k-\varepsilon$ models, the realizable $k-\varepsilon$ model satisfies certain mathematical constraints for the normal stresses which are consistent with the physics of turbulent flows [41]. The model constants are given in Table $\mathbf{1}$. 


\section{SST k- $\omega$ Model}

The shear-stress transport $k-\omega$ model (called SST in the present study), which is developed by Menter [42], is a modification of the standard $k-\omega$ model where the equation for the turbulent viscosity is modified to account for the transport of the principal turbulent shear stress [41]. The detailed model description can be found in [41-42,71].

\section{Reynolds Stress Model (RSM)}

In the RSM, the Reynolds stresses are calculated from their transport equations [47]. Closure for Reynolds stresses require six equations for the six independent Reynolds stresses, $\overline{u_{i} u_{j}}$, and another equation for the isotropic turbulence energy dissipation rate, $\varepsilon$. The Reynolds stress transport equations are expressed as

$\frac{\partial}{\partial t}\left(\rho \overline{u_{i} u_{j}}\right)+\frac{\partial}{\partial x_{k}}\left(\rho U_{k} \overline{u_{i} u_{j}}\right)=D_{i j}+P_{i j}+\phi_{i j}-\varepsilon_{i j}$

where $D_{i j}, P_{i j}, \phi_{i j}$ and $\varepsilon_{i j}$ represent, respectively, the diffusion, production, pressure-strain, and viscous dissipation.

It should be noted that in the present study, instead of using the generalized gradient-diffusion model of Daly and Harlow [72] for the $D_{i j}$ term, the simplified model equation, which is reported in [73], is used. It is expressed as

$D_{i j}=\frac{\partial}{\partial x_{k}}\left(\frac{\mu_{t}}{\sigma_{k}} \frac{\partial \overline{u_{i} u_{j}}}{\partial x_{k}}\right)$

and the stress production and dissipation terms of Eq. (10) are given as

$P_{i j}=-\rho \overline{u_{i} u_{k}} \frac{\partial U_{j}}{\partial x_{k}}-\rho \overline{u_{j} u_{k}} \frac{\partial U_{i}}{\partial x_{k}}$

$\varepsilon_{i j}=-\frac{2}{3} \rho \delta_{i j} \varepsilon$

The main focus of $R S M$ is on the pressure-strain term [74-77]. The turbulence energy dissipation rate, $\varepsilon$, is obtained by solving the following transport equation below. The model constants are provided in Table 2.

$$
\begin{aligned}
\frac{\partial(\rho \varepsilon)}{\partial t}+\frac{\partial\left(\rho \varepsilon U_{i}\right)}{\partial x_{i}}=\frac{\partial}{\partial x_{j}} & {\left[\left(\mu+\frac{\mu_{t}}{\sigma_{\varepsilon}}\right) \frac{\partial \varepsilon}{\partial x_{j}}\right] } \\
& +\frac{1}{2} C_{\varepsilon 1} \frac{\varepsilon}{k} P_{i i}-C_{\varepsilon 2} \rho \frac{\varepsilon^{2}}{k}
\end{aligned}
$$

Table 2. The Reynolds Stress Models Coefficients

\begin{tabular}{|c|c|c|c|c|c|c|c|}
\hline & $\mathbf{C}_{\boldsymbol{\mu}}$ & $\mathbf{C}_{\mathbf{1}}$ & $\mathbf{C}_{\mathbf{1}}{ }^{*}$ & $\mathbf{C}_{\mathbf{2}}$ & $\mathbf{C}_{\mathbf{3}}$ & $\mathbf{C}_{3}{ }^{*}$ & $\mathbf{C}_{\mathbf{4}}$ \\
\hline \hline RSM & 0.09 & 1.8 & - & 0.6 & - & - & - \\
\hline SSG & 0.09 & 3.4 & 1.8 & 4.2 & 0.8 & 1.3 & 1.25 \\
\hline & $\mathrm{C}_{5}$ & $\mathrm{C}_{1 \varepsilon}$ & $\mathrm{C}_{2 \varepsilon}$ & $\mathrm{C}_{1}{ }^{\prime}$ & $\mathrm{C}_{2}{ }^{\prime}$ & $\sigma_{\mathrm{k}}$ & $\sigma_{\varepsilon}$ \\
\hline RSM & - & 1.44 & 1.92 & 0.5 & 0.3 & 1 & 1.3 \\
\hline SSG & 0.4 & 1.44 & 1.83 & - & - & 1 & 1.3 \\
\hline
\end{tabular}

\section{Quadratic Pressure-Strain (SSG) Model}

The SSG uses a quadratic pressure-strain model instead of a linear pressure-strain model [59]. It is expressed as

$$
\begin{aligned}
& \phi_{i j}=-\left(C_{1} \varepsilon+C_{1}^{*} P\right) b_{i j}+C_{2} \varepsilon\left(b_{i k} b_{k j}-\frac{1}{3} b_{m n} b_{m n} \delta_{i j}\right) \\
& +\left(C_{3}-C_{3}^{*} \sqrt{b_{i j} b_{i j}}\right) k S_{i j}+C_{4} k\left(b_{i k} S_{j k}+b_{j k} S_{i k}\right. \\
& \left.-\frac{2}{3} b_{m n} S_{m n} \delta_{i j}\right)+C_{5} k\left(b_{i k} \Omega_{j k}+b_{j k} \Omega_{i k}\right)
\end{aligned}
$$

where $b_{i j}$ is the Reynolds stress anisotropy tensor given as

$b_{i j}=\frac{\overline{\mathrm{u}_{\mathrm{i}} \mathrm{u}_{\mathrm{j}}}}{2 k}-\frac{1}{3} \delta_{i j}$

with $S_{i j}$ and $\Omega_{i j}$ are the mean rate of the strain tensor and the mean vorticity tensor, respectively, which are defined as

$$
S_{i j}=\frac{1}{2}\left(\frac{\partial u_{j}}{\partial x_{i}}+\frac{\partial u_{i}}{\partial x_{j}}\right), \quad \Omega_{i j}=\frac{1}{2}\left(\frac{\partial u_{i}}{\partial x_{j}}-\frac{\partial u_{j}}{\partial x_{i}}\right)
$$

The model constants are tabulated in Table 2.

\subsection{Problem Definition and Solution Procedure}

The set of equations, which result from Eq.(2), are solved by the aid of the turbulence closure models described in the previous section. Their solution is applied for simulating swirling flows in a dump combustor. The geometry of the combustor is shown in Fig. (1).

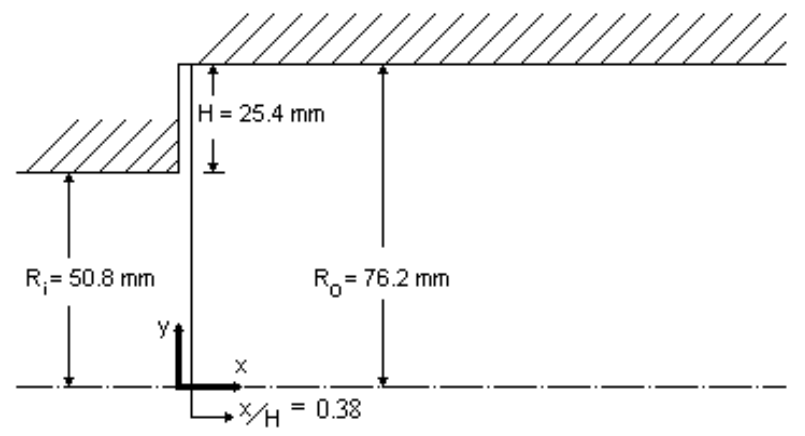

Fig. (1). Schematic of the combustor geometry.

In the present study, two flow configurations are simulated; referred to in the present paper as flow configuration with low and high swirl numbers, respectively.

Table 3. Inlet Flow Test Conditions

\begin{tabular}{|c|c|c|}
\hline & Case 1 & Case 2 \\
\hline \hline Inlet Centerline velocity & $19.2 \pm 0.4 \mathrm{~m} / \mathrm{s}$ & - \\
\hline Inlet average velocity & - & $30.4 \pm 0.3 \mathrm{~m} / \mathrm{s}$ \\
\hline Reynolds number & $1.25 \times 10^{5}$ & $1.98 \times 10^{5}$ \\
\hline Swirl number & 0.4 & 0.81 \\
\hline
\end{tabular}

The first one is airflow with an inlet centerline velocity of $19.2 \pm 0.4 \mathrm{~m} / \mathrm{s}$, which corresponds to a Reynolds number of $1.25 \times 10^{5}$ based on the combustor inlet diameter (see Fig. 
(1)). The swirl number in this configuration is 0.4 . The second configuration is an airflow with an inlet average velocity of $30.4 \pm 0.3 \mathrm{~m} / \mathrm{s}$, which corresponds to a Reynolds number of $1.98 \times 10^{5}$ based on the combustor inlet diameter. The swirl number in this case is 0.81 . Note that the Reynolds and swirl numbers in the second flow configuration are about 1.6 and 2 times those in the first one, respectively, which provide a wide range of flow conditions (see Table 3 ).

Experimental data for these two flow configurations are obtained from Refs. [63, 67]. Note that experimental data are available starting from $x / H=0.38$ downstream of the combustion sudden expansion. In the simulation exercise, the experimental data at this location are used as the inlet boundary conditions. The experimental data for the turbulent kinetic energy $(k)$ available at the inlet is used in the simulation. In order to calculate the dissipation rate of the turbulent kinetic energy $(\varepsilon)$ at the inlet, the following equation is used:

$\varepsilon=C_{\mu}^{3 / 4} k^{3 / 2} / l$

where $C_{\mu}$ is a constant $(=0.09), k$ is the turbulent kinetic energy, and $l$ is the turbulence length scale which can be approximated as 0.07 of the combustor diameter $(l=0.07 D)$. The flow is assumed steady, axisymmetric and isothermal. Because of the symmetry, only the upper half of the combustor is simulated. The computational domain is chosen to be long enough to ensure complete development of the flow; that is, up to $x / H=18$ in the first flow configuration and up to $x / H=24$ in the second one. A zero normal-gradient boundary condition is chosen at the outlet. A two-layer-based, nonequilibrium wall function [78] is used near the wall. In this model, the Launder and Spalding's [68] log-law for the mean velocity is sensitized to the effects of pressure-gradient, and it is also assumed that the wall-neighboring cells consist of a viscous sublayer and a fully turbulent layer [41]. In the present work, the wall-adjacent cell's centroid is located at $\mathrm{y}^{+} \approx 45$ in both flow cases.

The numerical mesh in the first flow configuration is chosen to be $64 \times 128$ in the axial and radial directions, respectively, while in the second case a mesh of $64 \times 160$ is employed. A non-uniform mesh (grid) is made finer near the inlet as well as close to both the combustor axis and the wall, whereas a coarser grid is used elsewhere. Grid independency is verified by doubling the number of mesh points in both cases.

To solve the governing equations, the FLUENT code, which is based on finite volume formulation, is employed. The PISO [79] method is applied for the pressure-velocity coupling. QUICK [80] scheme is used for the convection terms in all transport equations, and the PRESTO [41] method is used for the pressure discretization. The solution convergence is assumed when all of the residuals parameters fall below $10^{-5}$.

\section{RESULTS AND DISCUSSION}

The mean and fluctuating velocity components as well as the Reynolds shear stresses are compared against published measured data. Also, the velocity vectors and contours of the stream function are plotted for both low and high swirl intensity flow configurations.

\subsection{Low Swirl Number Flow Configuration}

\subsubsection{Mean Velocity Field}

Computational results of the normalized axial velocity are compared against their counterpart's published experimental data in Fig. (2a,b) at typical planes/stations in the near-, mid- and relatively far-fields of the flow. Three distinct regions can be observed; (i) a core region near the centerline of the combustor, (ii) a near wall region, and (iii) a mixing layer between these two regions. It can be seen that the size of each of these regions varies from one axial plane (or station) to another.
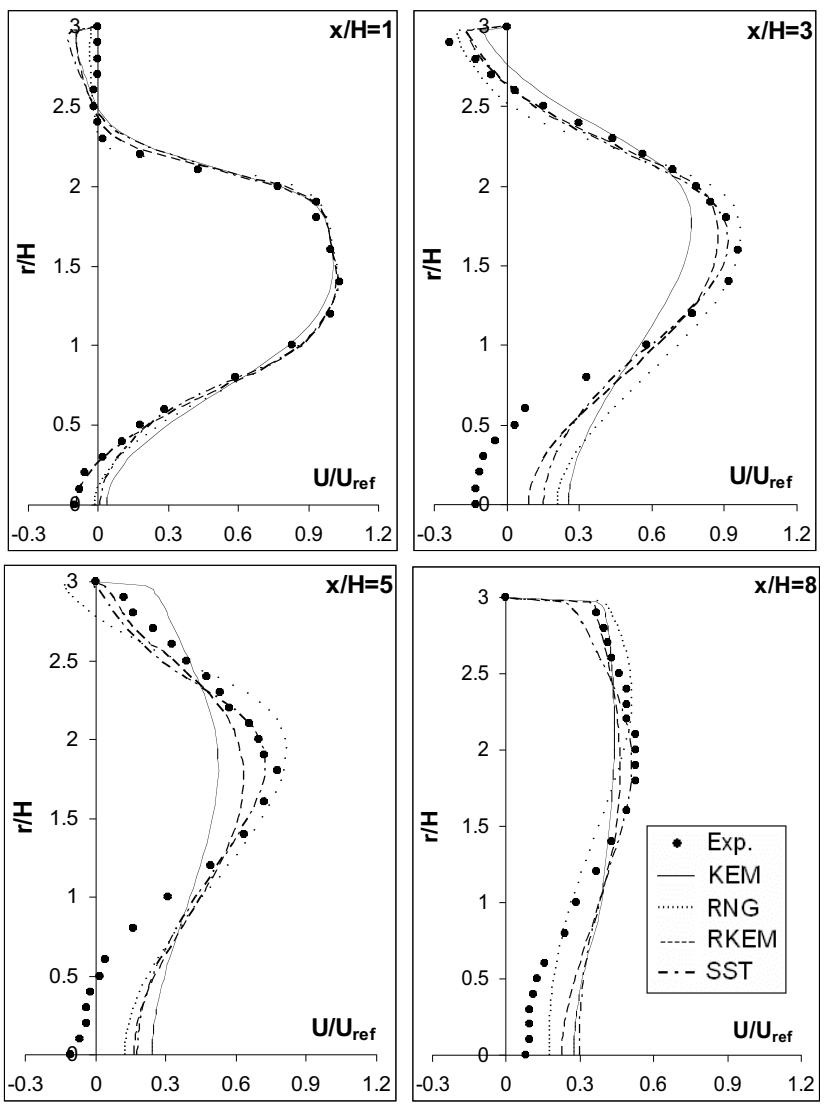

Fig. (2a). Radial profiles of normalized axial velocity $(S=0.4)$; Eddy-viscosity models.

As we can see in Fig. (2a), the maximum axial velocity at the inlet station occurs approximately halfway between the centreline (i.e. the axis of symmetry where $y=0$ in Fig. (1)) and the wall. However, as the flow progresses axially (downstream), the maximum axial velocity decays and shifts slightly towards the wall of the combustor. For example, at $x / H=1$, the maximum velocity is almost equal to the $U_{r e f}$, which occurs halfway radially (i.e. $r / H \sim 1.5$ ). However, at $x / H=8$, the maximum velocity is only $0.5 U_{r e f}$ and it is shifted towards the wall (i.e. $r / H \sim 2$ ). More importantly, these figures show clearly that the two-equation models predict a faster recovery of the axial velocity along the centerline. This characteristic of these types of models is also reported by Tsai et al. [18] and Lin et al. [81]. On the other hand, Fig. 
(2b) indicates that the stress models produce more accurate predictions than their counterparts' two-equation eddyviscosity models. For instance, in all the axial stations presented in Fig. (2a), the two-equation eddy viscosity models predict poorly the axial velocity near the centerline. Whereas, Fig. (2b) shows that the Reynolds stress models produce satisfactory predictions (with respect to the experimental data) everywhere including near the centreline.
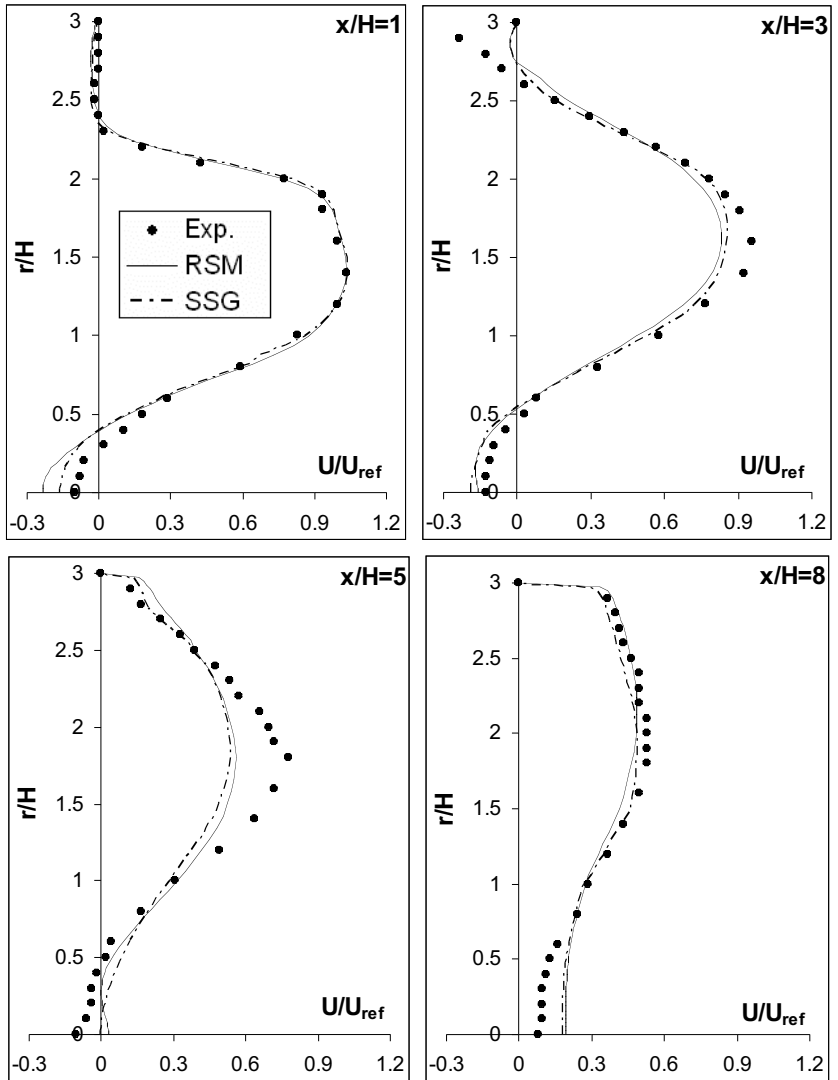

Fig. (2b). Radial profiles of normalized axial velocity $(S=0.4)$; Reynolds stress closures.

It can be concluded from Fig. $(\mathbf{2} \mathbf{a}, \mathbf{b})$ that the axial mean velocity at low swirl numbers in a cylindrical combustor with sudden expansion can be reasonably predicted by the Reynolds stress models. Among the two-equation eddyviscosity models, the $S S T$ model shows adequate predictions except near the axis of symmetry.

Computational results of the normalized tangential velocity are compared against published experimental data, as shown in Fig. (2c,d), for several axial stations representing the near and mid as well as far-fields of the flow development in the combustor. One can say that the maximum tangential velocity occurs at the first measurement station, which is near the flow onset. At subsequent stations beyond $x / H=10$ (not shown in this paper), the swirl profile for all the models becomes relatively flat, which is a characteristic of a tangential velocity profile generated by a constant-angle swirler [63]. Overall, the predictions beyond $x / H \sim 10$ are in good agreement with the experimental data of Ref. [63].
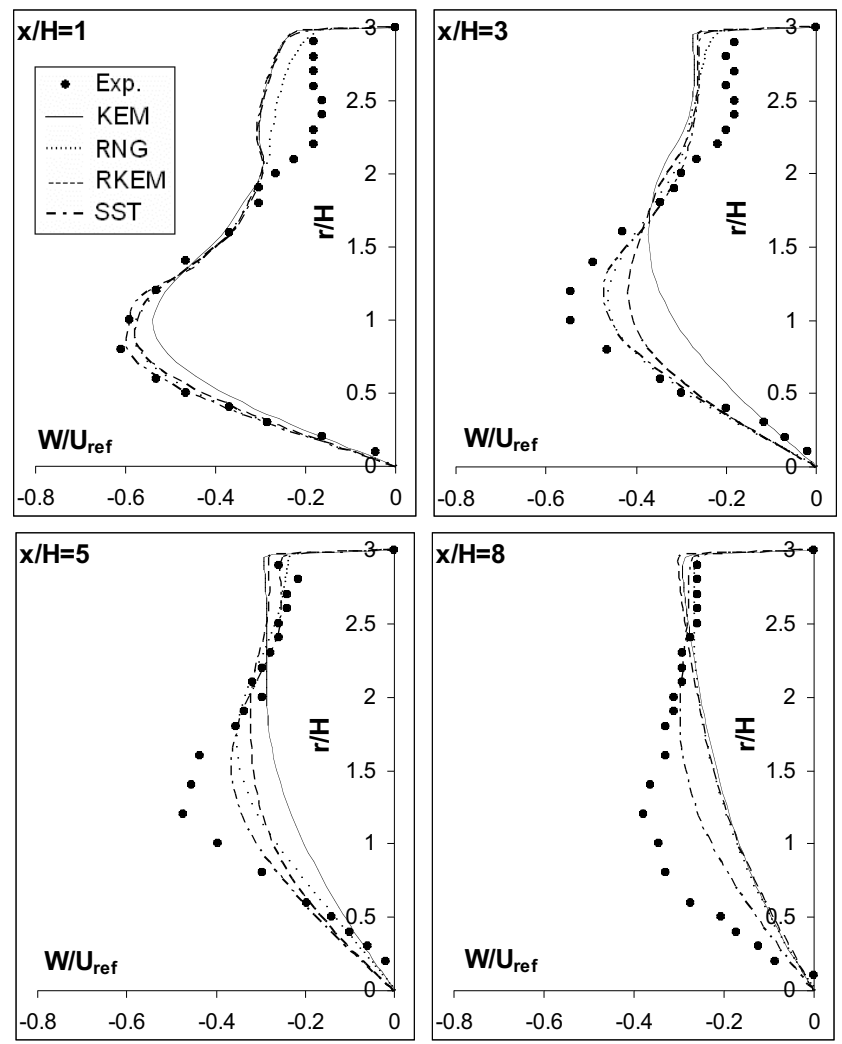

Fig. (2c). Radial profiles of normalized swirl velocity $(S=0.4)$; Eddy-viscosity models.
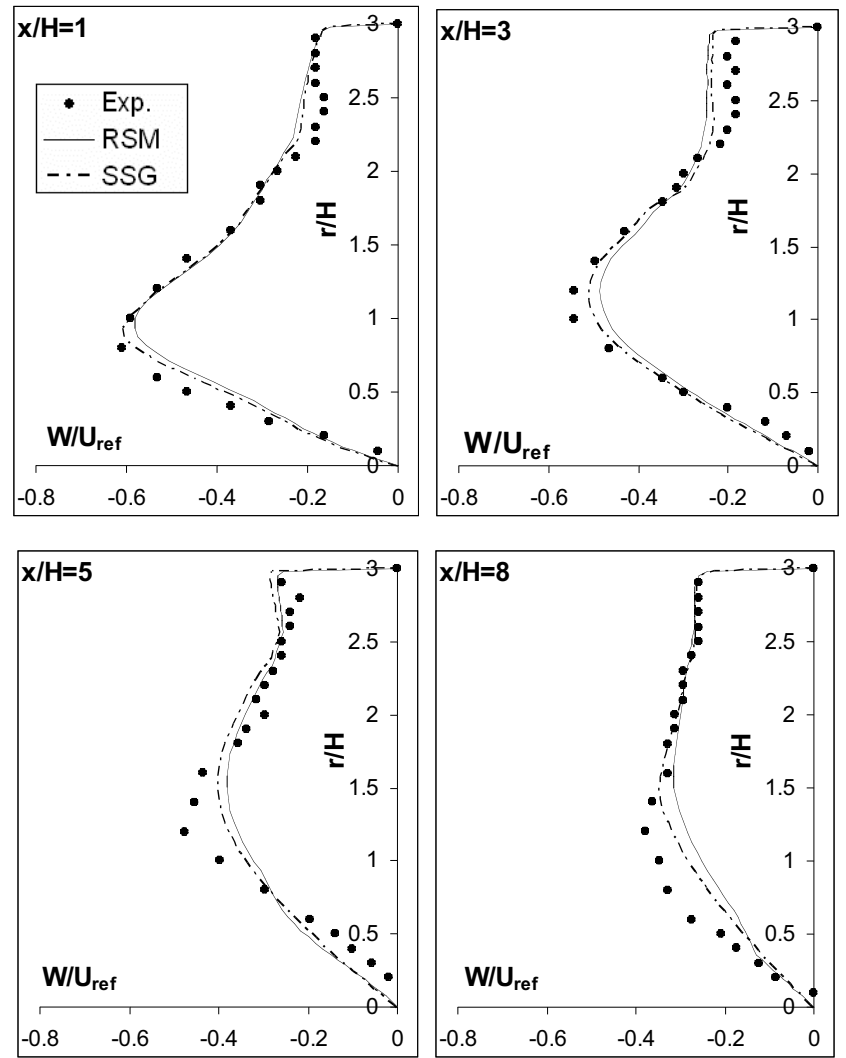

Fig. (2d). Radial profiles of normalized swirl velocity $(S=0.4)$; Reynolds stress closures 
As can be seen in Fig. (2c) at stations close to the dump plane (i.e. $x / H=1$ ), all the two-equation eddy-viscosity models predict poorly the tangential flow velocity especially near the wall. However as the flow develops downstream the dump plane, the same models do not perform well in the inner flow region (i.e. for $r / H<1.5$ ). On the other hand, the Reynolds stress models show reasonably satisfactory predictions of the tangential velocity profiles despite the fact that they slightly underpredict the maximum tangential velocity in the region between $r / H=0.5$ and $r / H=1.5$.

For this weakly swirling flow, $S=0.4$, one may conclude that among the two-equation eddy-viscosity models, the $K E M$ and SST show the worst and best predictions of the mean swirl velocity profiles, respectively. But the predictions of SST are still poor as compared to the experimental data. The predictions of the Reynolds stress models (e.g. $R S M$ and $S S G$ ), on the other hand, are much closer to the experimental data.

\subsubsection{Visualization of the Flowfield}

The velocity vectors and contours of stream function in the $U V$ plane at several typical locations representing the near-, mid- and far-fields of the flow development in the combustor are presented in Figs. $(\mathbf{3 , 4})$, respectively. The predictions in Fig. (4) indicate that the flowfield of a turbulent swirling flow in a dump combustor can be characterized by two distinct regions: (i) a corner recirculation zone (CRZ) that is caused by the sudden expansion of the cylindrical combustor, and (ii) a central toroidal recirculation zone (CTRZ) which is caused by an increase in the swirl intensity of the swirling flow. According to the experimental data [63], the CRZ starts in the dump plane and extends to roughly 4 step heights downstream of the dump plane.

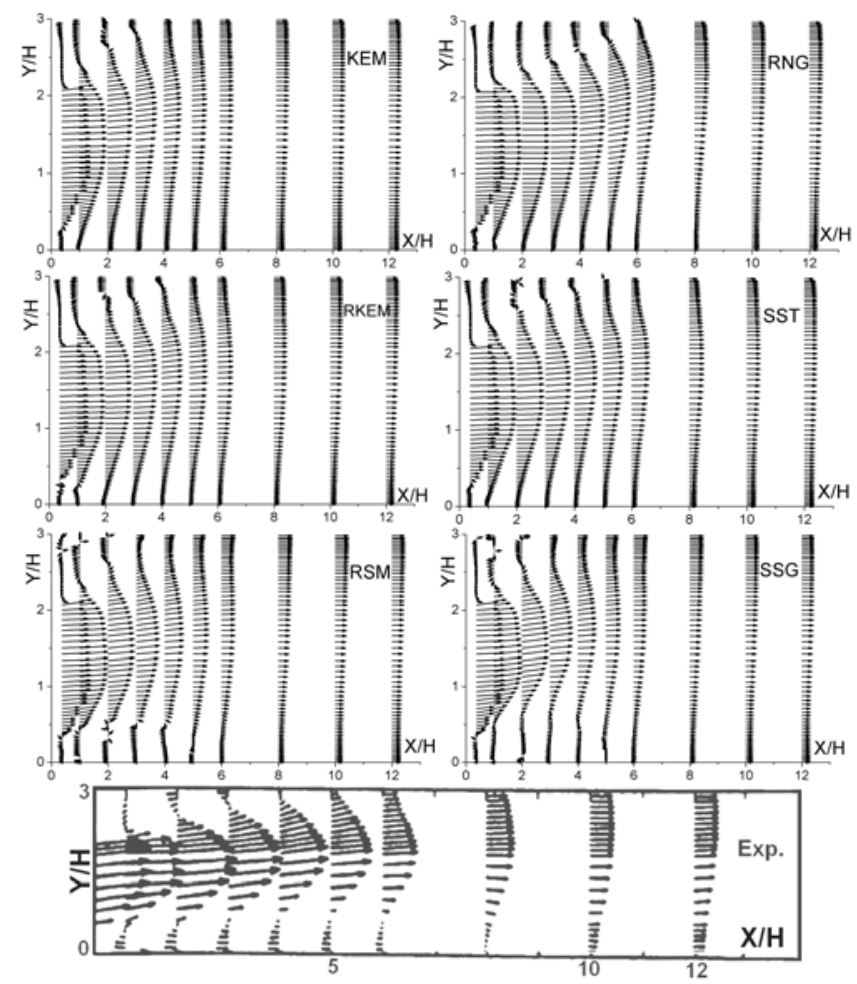

Fig. (3). Predicted and measured velocity vectors $(S=0.4)$.
Figs. $(3,4)$ show that all the tested turbulence models are able to predict the CRZ. The predicted length of the CRZ by these models is summarized in Table 4. This Table shows that the predicted length of the CRZ by the KEM is the best one when compared with its experimental counterpart. The predicted CRZs by the RNG, RKEM and the SST are longer than the one found experimentally, while the predicted CRZs by the $R S M$ and $S S G$ are shorter than their experimental counterpart.

Table 4. Measured and Predicted Length of the CRZ for $S=0.4$

\begin{tabular}{|c|c|c|c|c|c|c|}
\hline Exp. & KEM & RNG & RKEM & SST & RSM & SSG \\
\hline \hline 4 & 3.7 & 6 & 5 & 5 & 2.7 & 2.5 \\
\hline
\end{tabular}

It is found experimentally that the CTRZ starts in the inlet pipe upstream of the dump plane and extends to roughly 7.9 step heights downstream of the dump plane, with a maximum radius of $r / H=0.6$ at $x / H=5.0$ [63]. Figs. $(\mathbf{3 , 4})$ show that the KEM, RNG, RKEM and the SST cannot predict this important feature of the flow, while the $R S M$ and the $S S G$ models are able of capturing this feature.
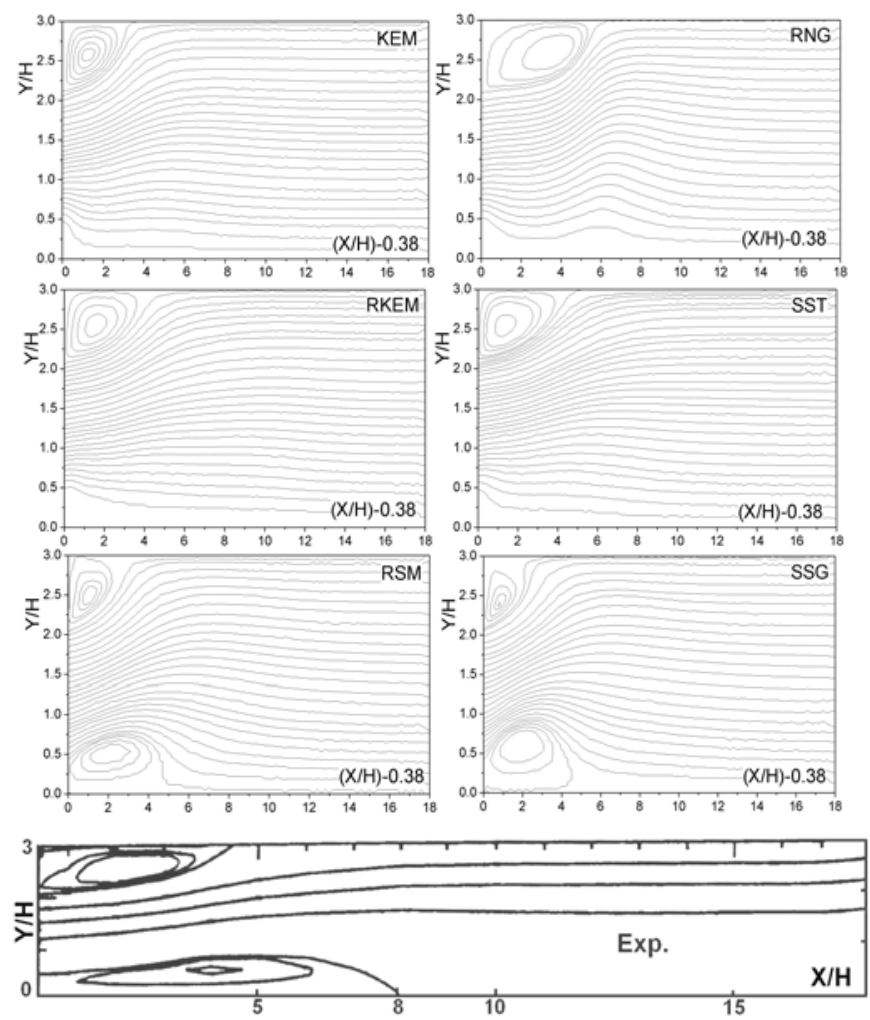

Fig. (4). Predicted and measured contours of stream function $(S=0.4)$.

The predicted CTRZ by the RSM extends to approximately 5 step heights downstream of the dump plane, with a maximum radius of $r / H=0.75$ at $x / H=3.5$ while that predicted by the $S S G$ extends to approximately 5 step heights downstream of the dump plane with a maximum radius of $r / H=0.9$ at $x / H=3$. This indicates that both the $R S M$ and the $S S G$ predict shorter (in axial direction) and wider (in the ra- 
dial direction) CTRZ, as compared to the experiments (see Table 5).

Table 5. Measured and Predicted Length and Width of the CTRZ for $S=0.4$

\begin{tabular}{|c|c|c|}
\hline & $(\mathbf{x} /)_{\max }$ & $(\mathbf{y} / \mathbf{H})_{\max }$ \\
\hline \hline Exp. & 7.9 & 0.6 \\
\hline KEM & - & - \\
\hline RNG & - & - \\
\hline RKEM & - & - \\
\hline SST & - & - \\
\hline RSM & 5 & 0.75 \\
\hline SSG & 5 & 0.9 \\
\hline
\end{tabular}

In conclusion, all the employed turbulence models can predict the CRZ, whereas only the Reynolds stress closures reveal the existence of the CTRZ. The size of the CRZ is reasonably well predicted by the $K E M$ model, while the $R S M$ model produces slightly smaller CRZ. The RSM shows better predictions of the size of the CTRZ than that of the $S S G$, although the predicted size of the CTRZ is still around $40 \%$ shorter in length than its experimental counterpart.

\subsubsection{Turbulence Quantities}

Fig. (5a-d) show the radial profiles of the measured and predicted turbulence intensity components and two of the Reynolds shear stress components (i.e. $\overline{u^{\prime} v^{\prime}}$, and $\overline{u^{\prime} w^{\prime}}$ ) at different axial locations (i.e. near- mid- and far-field).
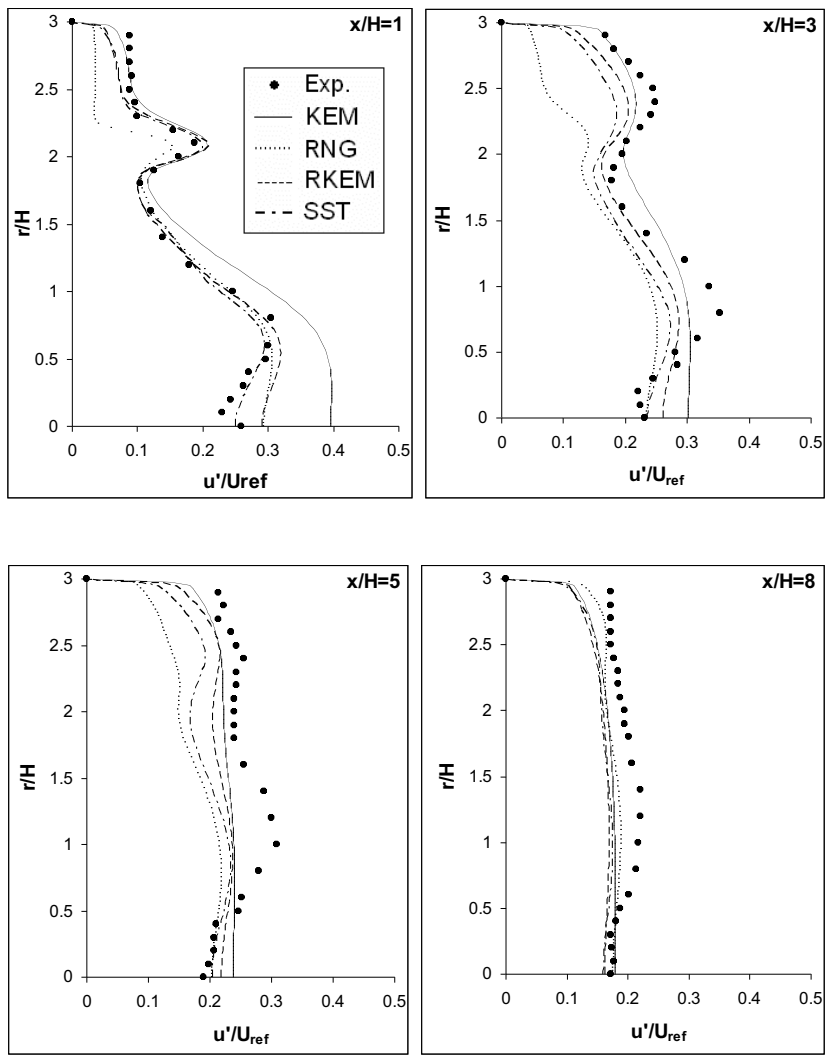

(Fig. 5a) contd.....
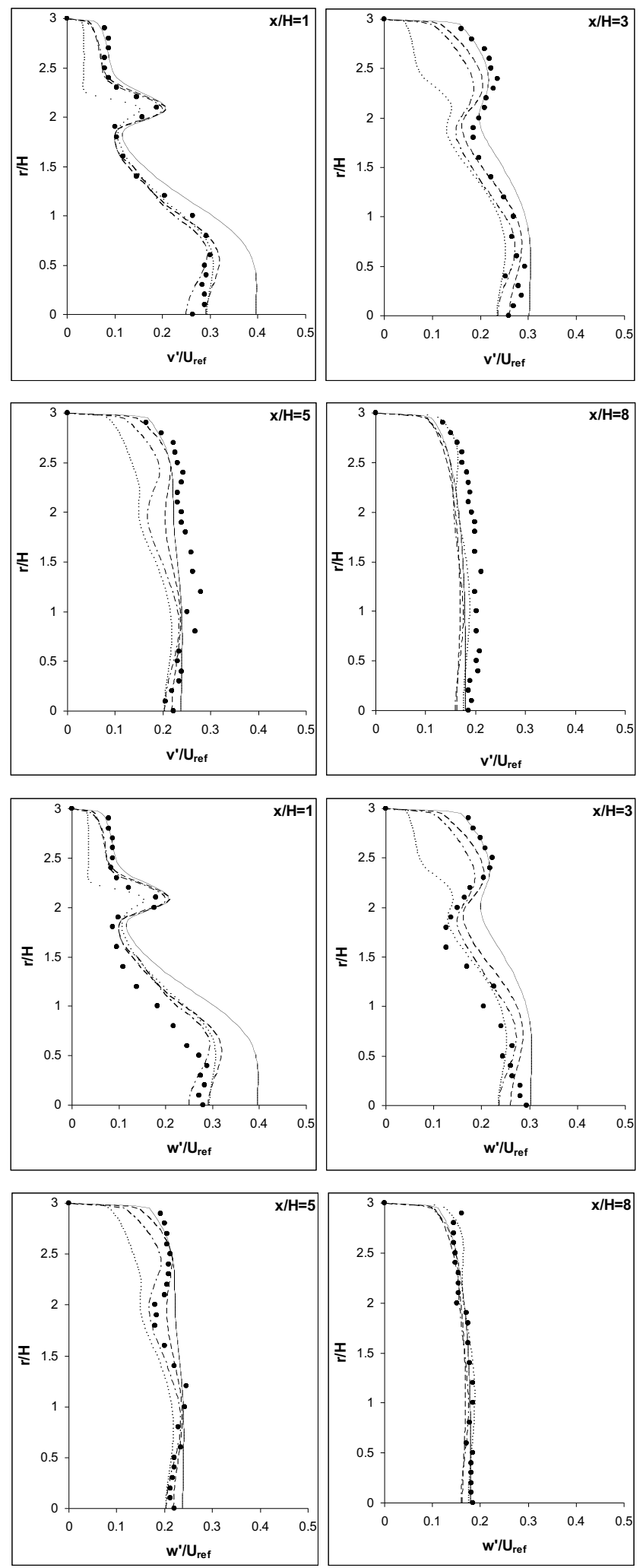

Fig. (5a). Radial profiles of normalized turbulence intensities $(S=0.4)$; Eddy-viscosity models.

The experimental data of the normalized $u^{\prime}$ shown in Fig. (5a,b) reveal two peaks at each axial location in the near- and mid-field. One peak is located in the shear layer between the main flow and the CTRZ, and the other one can 
be seen in the shear layer between the main flow and the CRZ. Comparing the values of these two peaks, it can be noted that the turbulent activity in the central shear layer is stronger than the activity in the outer shear layer. This characteristic of the flow is captured by all the models. The experimental data show a maximum turbulence intensity at $x / H=3$, while all the tested models predict a maximum turbulence intensity at $x / H=1$, except the $S S G$ which shows almost the same level of turbulence at $x / H=1$ and $x / H=3$. The $K E M$ overpredicts the turbulence intensities in the inner region at $x / H=1$. In the near- and mid-filed, the $R N G$ shows very poor results in the region $r / H>2$.

A similar trend is observed for the radial and tangential turbulence intensity profiles. The KEM overpredicts $v^{\prime}$ and $w^{\prime}$ in the inner region at $x / H=1$, and $x / H=3$, while the $R N G$ underpredicts these components of the turbulence intensity in the region $r / H>2$ for the near- and mid-field. Between the Reynolds stress closures, the $S S G$ performs better at $x / H=1$, while the predictions of $R S M$ are competitive with those of the SSG in the mid- and far-field. As reported by other
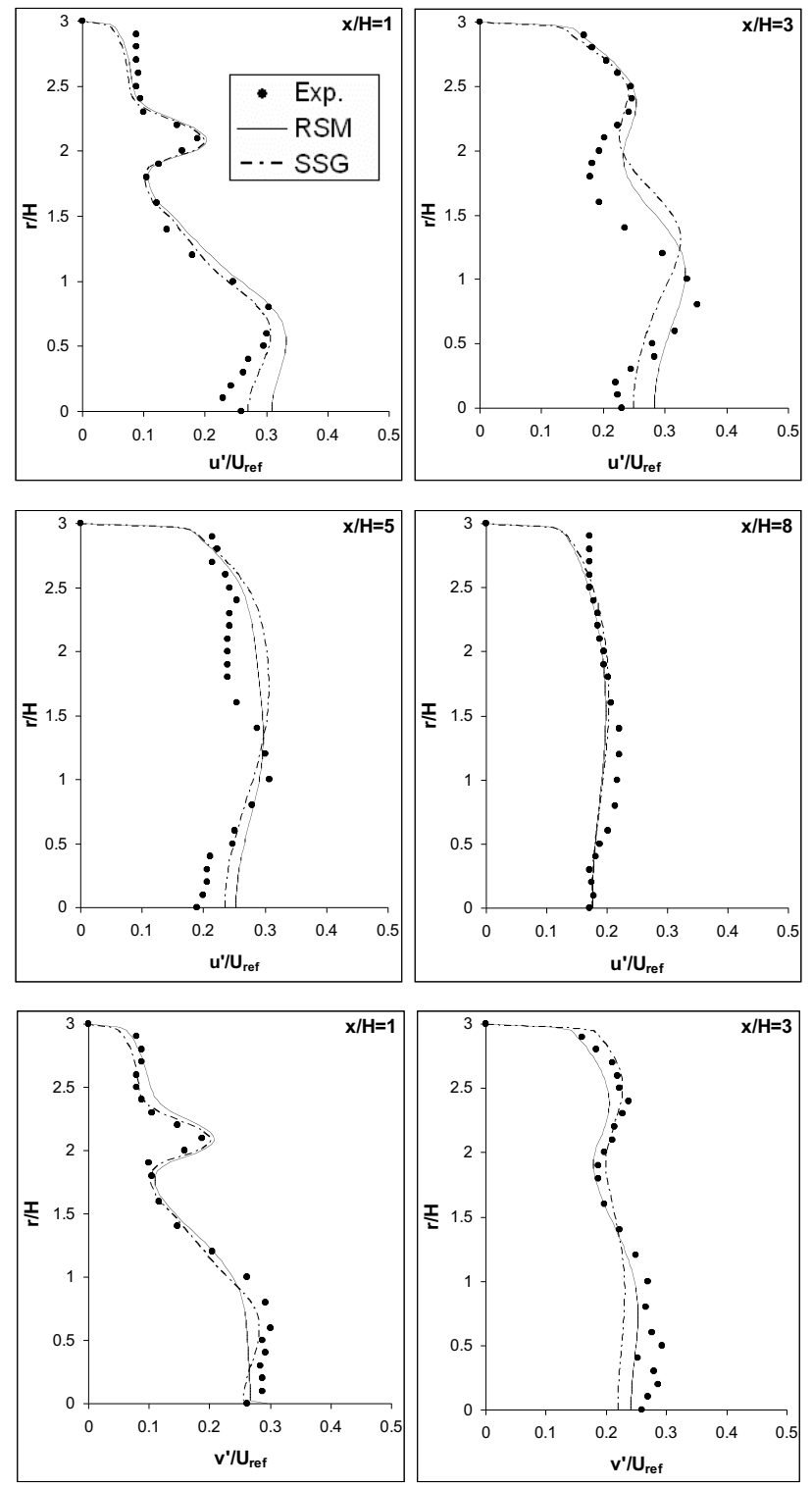

(Fig. 5b) contd.....
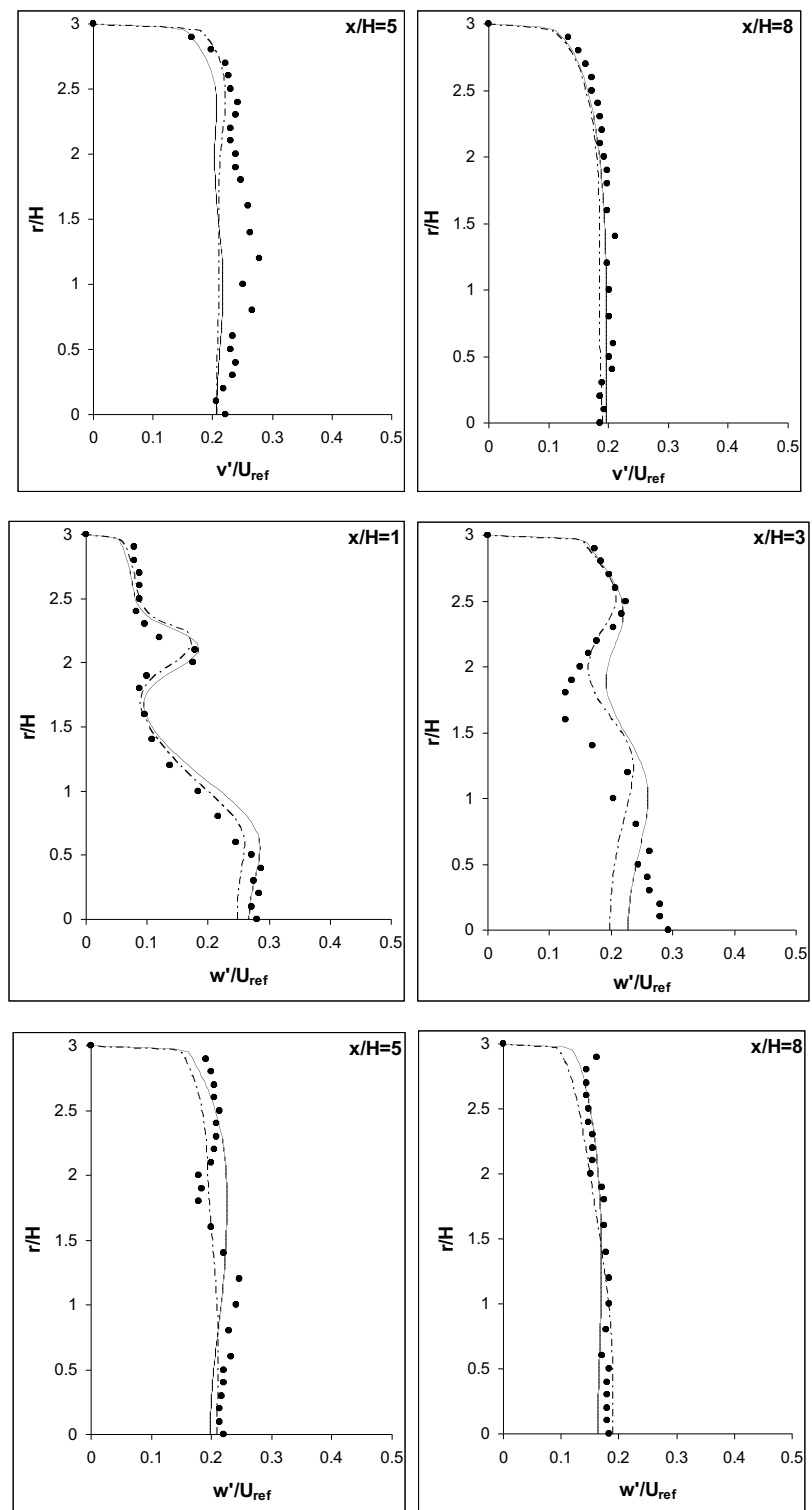

Fig. (5b). Radial profiles of normalized turbulence intensities $(S=0.4)$; Reynolds stress closures.

authors [50], the value of $v^{\prime}$ and $w^{\prime}$ is under-predicted by the Reynolds stress closures near the centerline in the midfield. In the far field, all the numerical predictions of the turbulence intensities are in good agreement with the relatively flat experimental trends (profiles). Similar to the numerical results for the mean velocity components, the predictions of the Reynolds stress models for the turbulence intensities are more accurate than those obtained by the eddyviscosity models.

Profiles of the Reynolds shear stresses presented in Fig. (5c,d), show that $\overline{u^{\prime} v^{\prime}}$ changes sign across the combustor. The shear stresses in the far-field are insignificant indicating full recovery of the flow inside the combustor. At $x / H=1$, in the region $r / H<1.5, \overline{u^{\prime} v^{\prime}}$ is overpredicted by a factor of 3 or more by all the eddy-viscosity models, except the SST. In the mid-field the $S S T$ shows good results, especially in the outer 

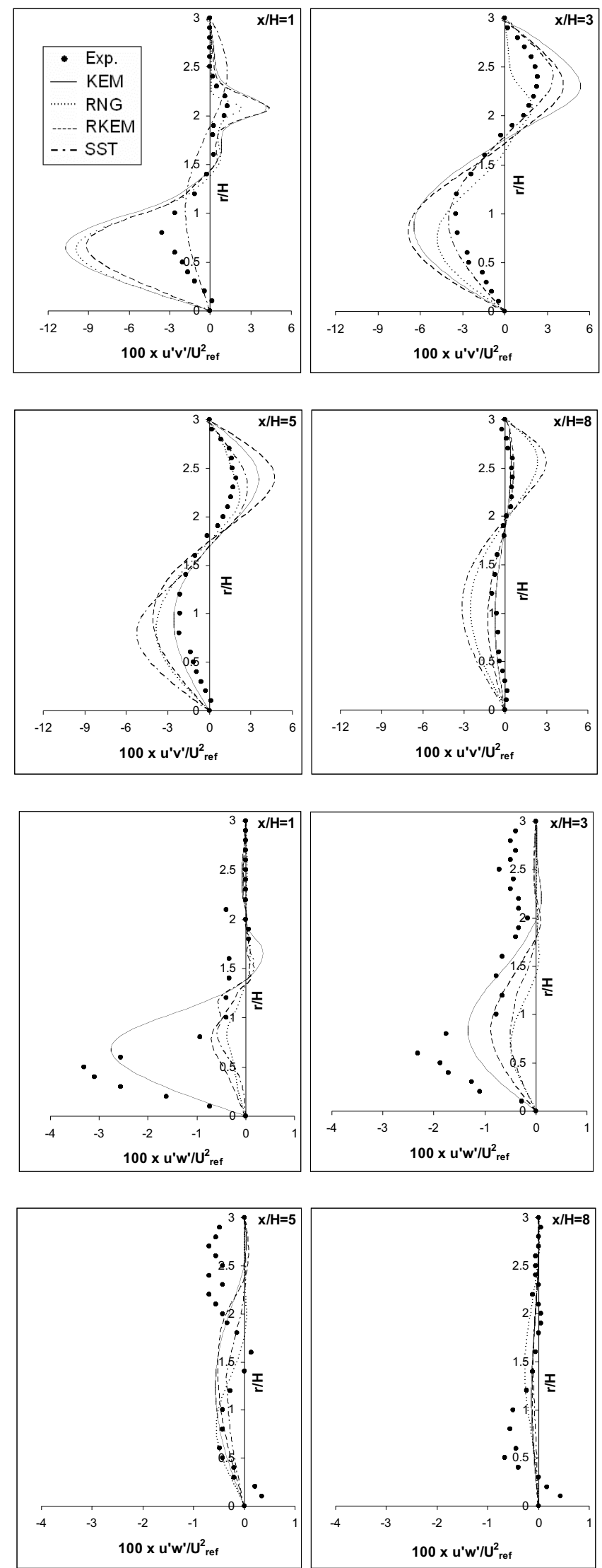

Fig. (5c). Radial profiles of normalized shear stresses $(S=0.4)$; Eddy-viscosity models.
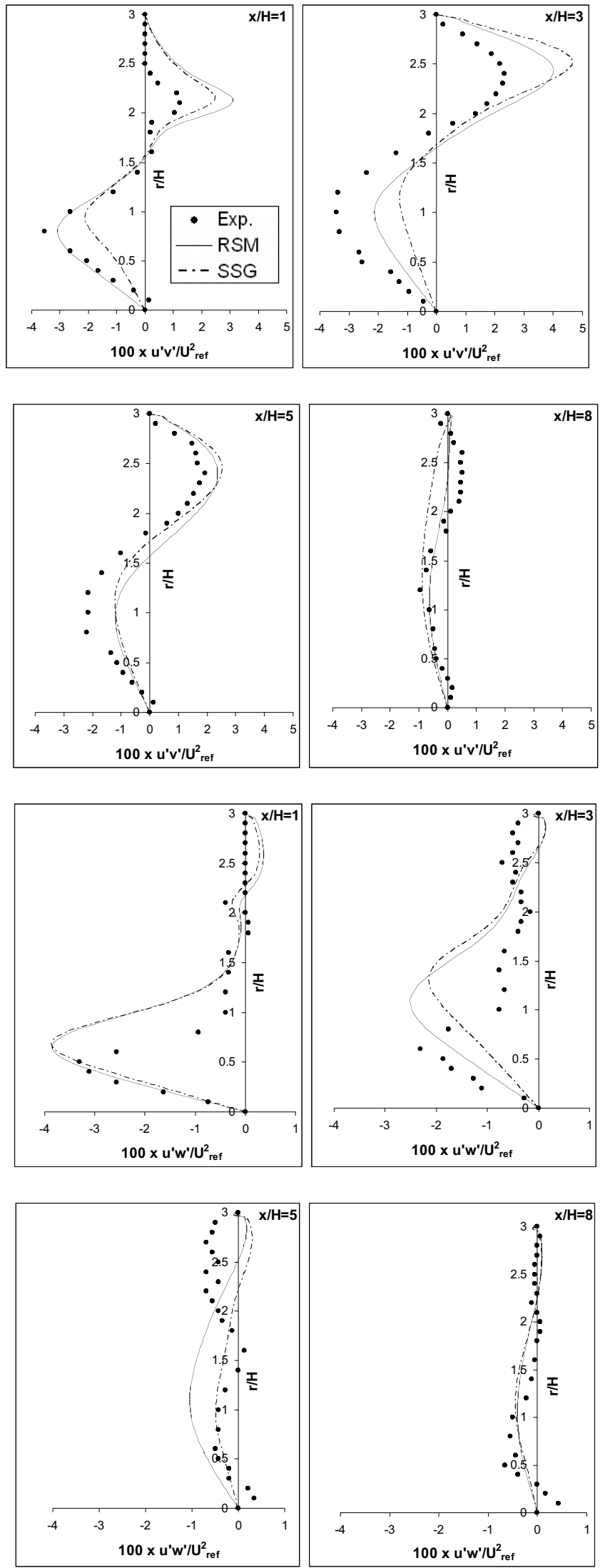

Fig. (5d). Radial profiles of normalized shear stresses $(S=0.4)$; Reynolds stress closures. 
region, while the predictions of the KEM and the RKEM in the far-field are very close to that of the experiment. On the other hand, the Reynolds stress models are in fairly good agreement with the measured $\overline{u^{\prime} v^{\prime}}$ data, except at $x / H=3$ where they show the same trend as the measured data, but with different magnitude.

The second component of the Reynolds shear stresses, $\overline{u^{\prime} w^{\prime}}$, shows one peak close to the CTRZ boundary, at $x / H=1$ and $x / H=3$ after which it rapidly loses its strength and becomes insignificant. In the near-filed, all the eddy viscosity models underpredict $\overline{u^{\prime} w^{\prime}}$ by a factor of 5 in the inner region, except the $K E M$ which shows much more accurate results. At $x / H=1$ there is no a visible difference between the Reynolds stress models predictions. At this axial location, the $R S M$ and the $S S G$ show accurate enough results except near the wall. In the mid-field, none of the models shows satisfactory results, while in the far-field, the magnitude of $\overline{u^{\prime} w^{\prime}}$ is so low that there is not much difference between the predictions and experiments.

In conclusion, among the eddy-viscosity models, the $R K E M$ is the best model in predicting the turbulence intensity components, while more accurate results of the Reynolds shear stresses can be obtained by employing the KEM. On the other hand, the Reynolds stress closures show superior results in predicting the turbulence flowfield in this case study. The performance of the $R S M$ and the $S S G$ is competitive.

\subsection{High Swirl Number Flow Configuration}

\subsubsection{Mean Velocity Field}

Fig. (6a-d) present a comparison of the predicted profiles of the normalized axial and tangential velocities with their counterparts' experimental data at typical stations representative of the near-, mid- and far-fields of the flow.

Similar to the weakly swirling flow, it is clear from Fig. (6a) that the evolution size of the three radial regions (i.e. a core area near the axis, a near wall region and a mixing layer in between) of the axial velocity profiles, which varies as the flow develops downstream the onset point, is generally captured by all the two-equation eddy-viscosity models. This figure shows that the maximum axial velocity is located approximately halfway between the centerline and the wall in the near-field, and shifts towards the wall in the mid- and far-fields. In addition, Fig. (6a) shows that there are two reverse flow regions that can be seen at $x / H=1$, which is an indication of the existence of the CRZ and the CTRZ. The maximum axial velocity at $x / H=1$ is located at $r / H=1.7$ according to both the measurements and the stress models predictions. All the two-equation eddy-viscosity models underpredict the value of the maximum axial velocity, and only the $K E M$ predicts accurately the maximum axial velocity. In the near-field, that is at $x / H=1$, the $K E M$ shows the worst results in the core region and the wall region. On the other hand, Fig. (6b) shows that the Reynolds stress models produce good agreement with the measurements.
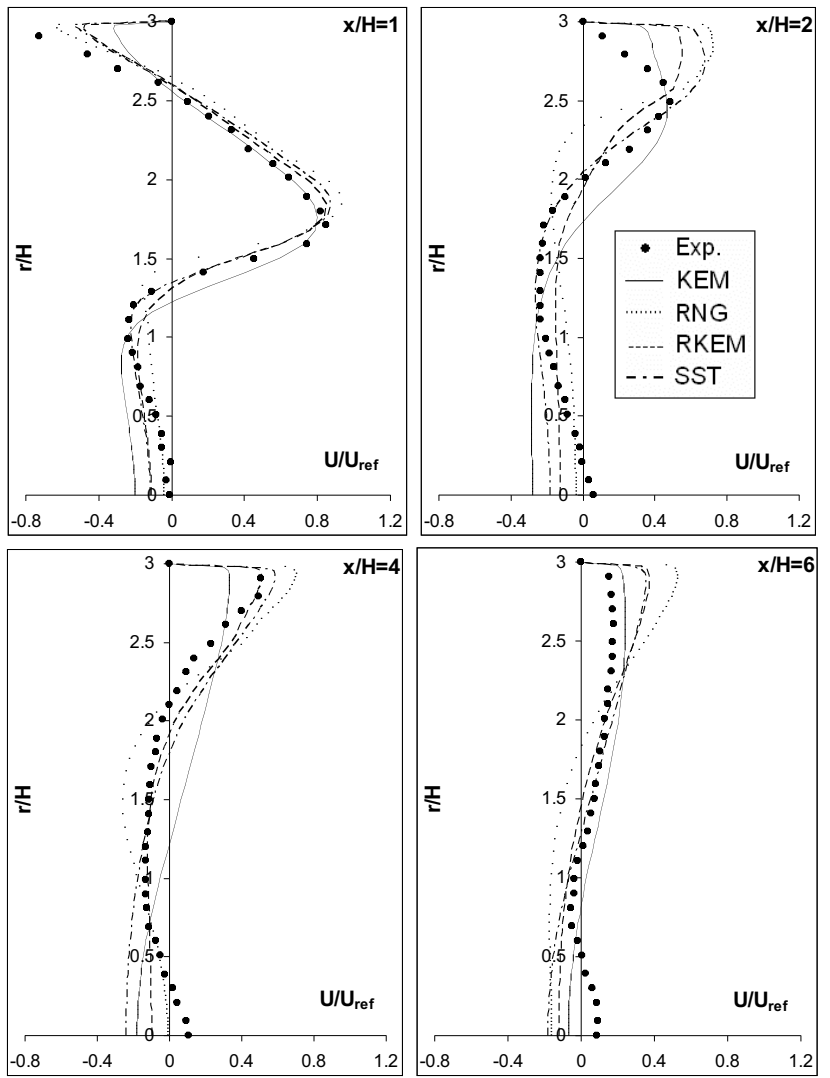

Fig. (6a). Radial profiles of normalized axial velocity $(S=0.81)$; Eddy-viscosity models.
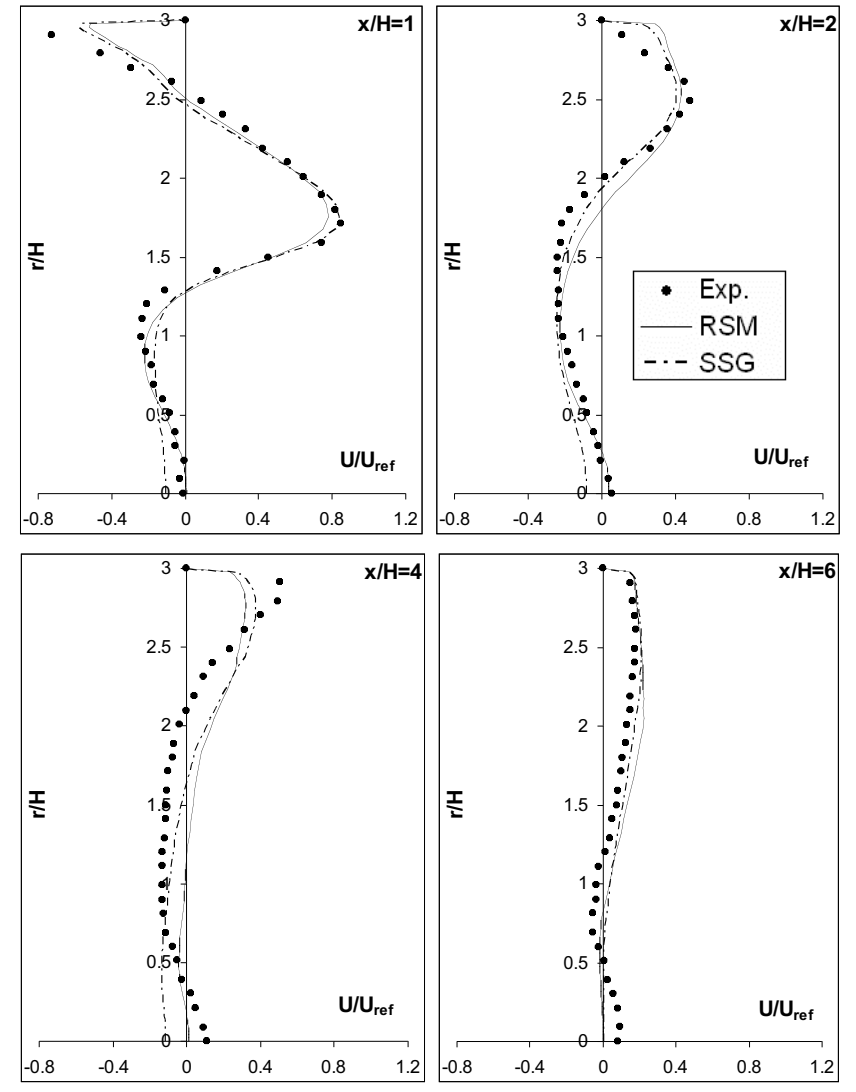

Fig. (6b). Radial profiles of normalized axial velocity $(S=0.81)$; Reynolds stress closures 
In the mid- and far-field regions, the $R N G$ shows poor predictions, especially in predicting the size of the reverse flow regions and the axial velocity profiles near the wall. The Reynolds stress models produce more accurate predictions than the two-equation eddy-viscosity models in the mid-field and far-field of the flow. It can be observed that in the far-field region, as shown in Fig. $(\mathbf{6 a}, \mathbf{b})$, that the strength of the flow is near the wall region, $r / H>2$. In this particular region, the $R N G$, the $R K E M$ and the $S S T$ show very poor predictions, whereas the predictions of the KEM, the RSM and the $S S G$ are in good agreement with the measurements.

The predictions of the normalized tangential velocity profiles and their comparison with the experimental data are presented in Fig. $(\mathbf{6 c}, \mathbf{d})$ at typical stations representative of the near-, mid- and far-fields of the flow.
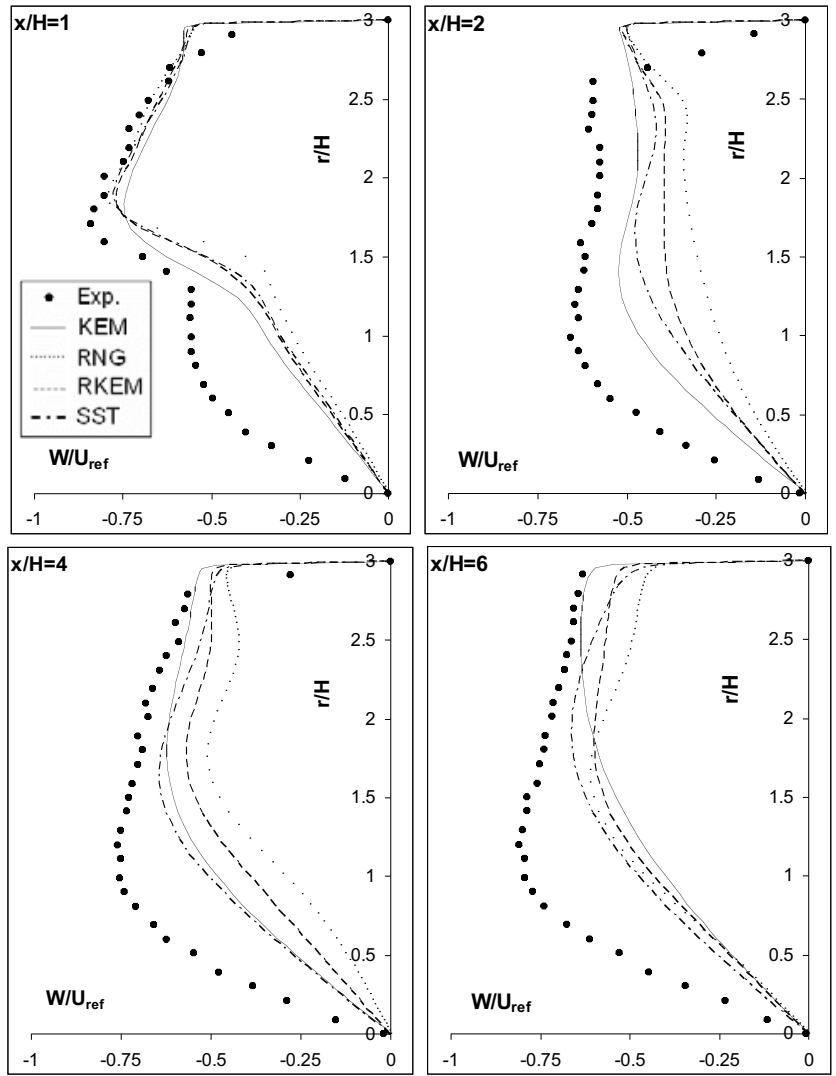

Fig. (6c). Radial profiles of normalized swirl velocity $(S=0.81)$; Eddy-viscosity models.

It can be seen from these figures that the swirl maximum velocity is at $r / H=1$ and remains almost unchanged beyond $x / H=2$. The exception occurs in the far-field near the wall region where small changes in the swirl velocity are observed as a result of frictions. At $x / H=1$, the swirl velocity has two local maxima, one at $r / H=1$, and another at $r / H=1.75$. In the experimental work [67], it is reported that at $x / H=0.38$, the flow behaves in a swirling jet-like fashion with a weak solid body rotation around the combustor axis. Also, it is mentioned that the forced vortex rotation near the combustor axis increases in strength due to mixing as it is demonstrated by the increasing swirl velocity gradient. Outside the core region, swirl velocity decreases in a fashion similar to free vortex behaviour. Fig. (6c) shows clearly that none of the two-equation models can predict properly the tangential velocity profiles, in which the $R N G$ and the KEM show the worst and the best predictions, respectively. Whereas the stress models exhibit more accurate predictions than the two-equation models. In particular, the SSG performs better in the near-field and also at $r / H>1.2$ in the midfield and far-field, while the RSM shows better predictions at $r / H<1.2$ in the mid-field and far-field.
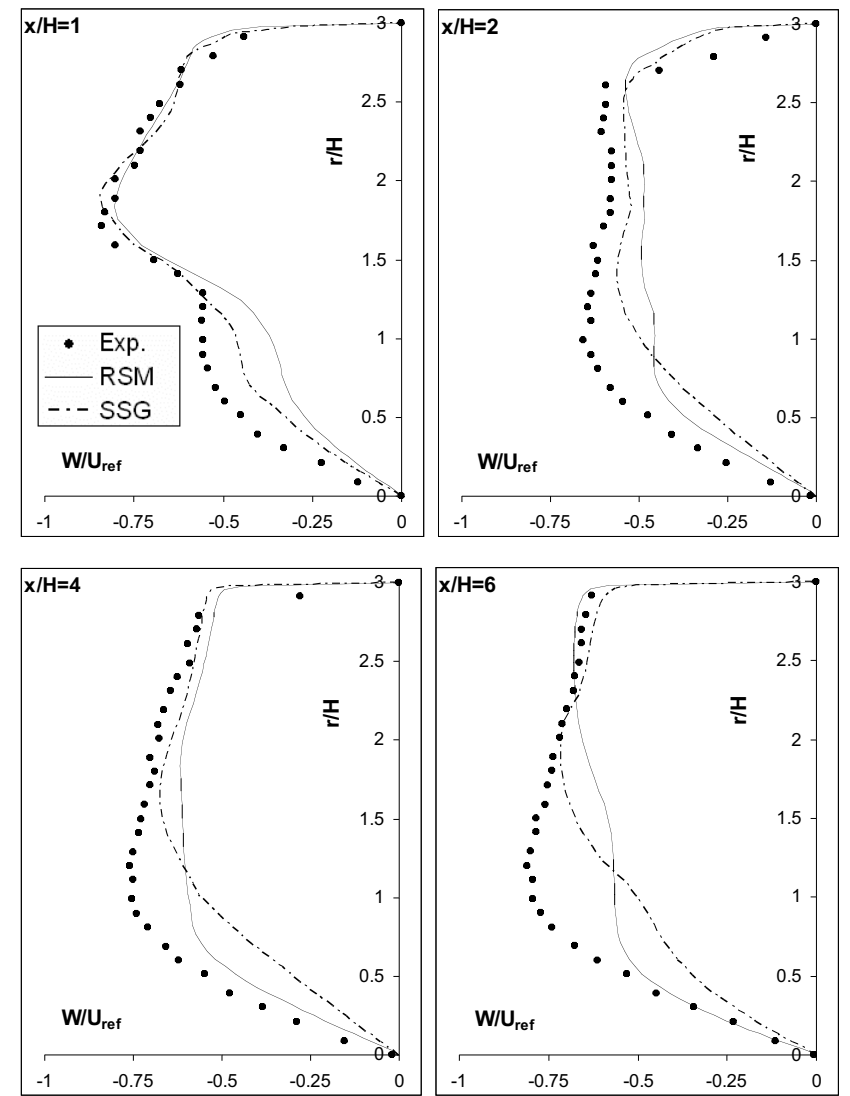

Fig. (6d). Radial profiles of normalized swirl velocity $(S=0.81)$; Reynolds stress closures.

\subsubsection{Visualization of the Flowfield}

The velocity vectors and contours of stream function are presented in Figs. $(\mathbf{7 , 8})$ at different locations along the combustor length. From the experimental data [67], the following reverse flow regions can be observed: (i) a counterclockwise rotating corner recirculation zone (CRZ), and (ii) a clockwise rotating central toroidal recirculation zone (CTRZ) which is connected with a central reverse flow region (CRR). It is reported in the experiment [67] that the size of the CRZ is 1.8 step heights. As we can see in Figs. $(7,8)$, all the tested models can predict the existence of the CRZ in the flowfield. The predicted size of the corner reverse flow region (CRR) is in good agreement with the experiment data for all the turbulence models. Measurements show that after the corner flow reattachment point, the near wall flow adjusts itself to be approximately parallel to the combustor centerline in the far-field. From the predicted contours of stream function, which is shown in Fig. (8), it is demonstrated clearly that this phenomenon is captured by all the turbulence models tested here, except the $R N G$ which shows streamlines non-parallel to the combustor axis in the 
far-field near the wall region. Also, experimental data [67] show that the CTRZ starts upstream of the dump plane and extends to roughly 6 step heights downstream of the dump plane with a maximum radius of $r / H=2.4$ at $x / H=2.5$. The centre of this recirculation zone is located approximately at $r / H=2.1$ and $x / H=2.4$.

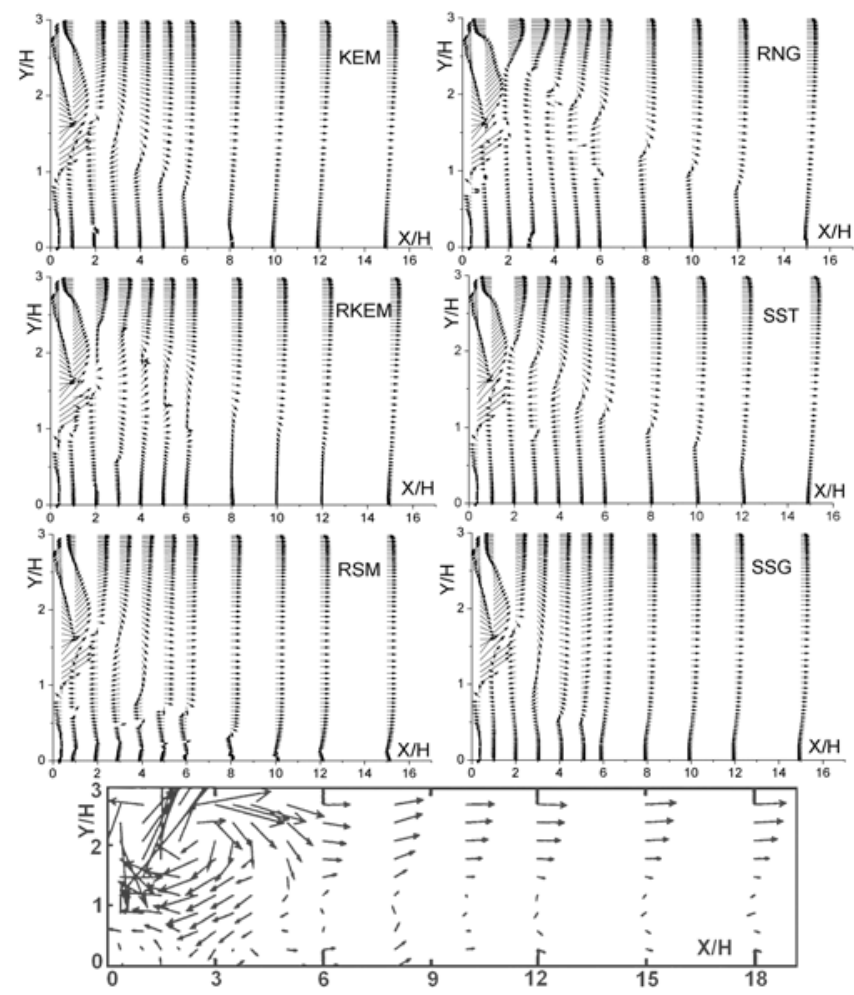

Fig. (7). Predicted and measured velocity vectors $(S=0.81)$.

It can also be seen in the experimental data that the CTRZ is connected with the CRR which extends all the way downstream up to the outlet of the combustion chamber. Figs. $(\mathbf{7}, \mathbf{8})$ show that all the employed models can predict the CTRZ, but with different shapes and sizes.
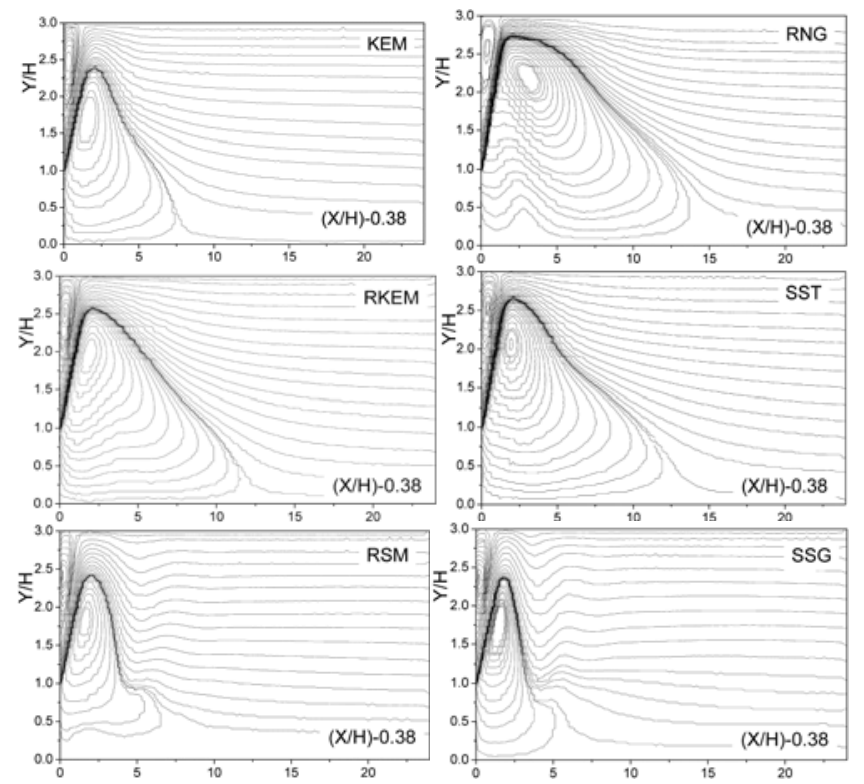

Fig. (8). Predicted contours of stream function $(S=0.81)$.
The predicted length (in $x$-direction) and width (in $y$ direction) of the CTRZ by these models is summarized in Table 6. The predicted sizes of the CTRZ by the stress models are better than those of the two-equation models. The predictions of the CTRZs by the $R N G$, the RKEM and the $S S T$ are much longer than the experimental value. Inadequacy of the two-equation models to accurately predict the size of the CTRZ is mainly due to the isotropic eddy viscosity assumption, while the flowfield is highly anisotropic, especially in the near-field.

Table 6. Measured and Predicted Length and Width of the CTRZ for $S=0.81$

\begin{tabular}{|c|c|c|}
\hline & $\left(\mathbf{x} / \mathbf{H}_{\max }\right.$ & $(\mathbf{y} / \mathbf{H})_{\max }$ \\
\hline \hline Exp. & 6 & 2.4 \\
\hline KEM & 7.5 & 2.4 \\
\hline RNG & 14 & 2.75 \\
\hline RKEM & 12 & 2.6 \\
\hline SST & 12.5 & 2.7 \\
\hline RSM & 7 & 2.4 \\
\hline SSG & 5.5 & 2.35 \\
\hline
\end{tabular}

As mentioned previously, the experimental velocity profiles show that a region of reverse flow (CRR) exists even far downstream of the dump plane. Therefore, one can say that the axial flow does not recover and the velocity distribution is far from the fully developed turbulent pipe flow. From the predictions of the velocity vectors in the $U V$ plane, shown in Fig. (7), it is clear that only the $R N G$ and the $R S M$ can capture this phenomenon all the way up to the outlet of the combustor. All the other models predict a fast recovery of the axial velocity near the combustor axis. The turbulence models KEM, RKEM, SST and SSG predict no reverse flow beyond $x / H=10,12,12$, and 8 , respectively.

In conclusion, for the flow configuration with high Swirl numbers, that is for $S=0.81$, it is found that the two-equation eddy viscosity models predict reasonably well the axial velocity only in the near flow-field and poorly elsewhere. However, the same axial velocity profiles are generally reasonably predicted by the Reynolds stress models. As for the tangential velocity profiles, the two-equation eddy-viscosity models show poor predictions, whereas the combination of the two $R S M$ and $S S G$ models produce good predictions. Indeed, in the near-field, the $S S G$ model produce the best profiles everywhere except near the centreline where the tangential velocity is underpredicted to less than $10 \%$ as compared to their experimental counterparts. In the mid and far fields, the $R S M$ model shows superior predictions than the $S S G$ model, although the tangential velocity is underpredicted, especially near the centreline, to less than $15 \%$ in the mid field and less than $25 \%$ in the far-field. It is also found that the predicted size of the CRZ by all the two-equation as well as the Reynolds stress models is in good agreement with the experimental data. In addition, all these models can predict the CTRZ, though with different sizes. The predicted 
length and width of the CTRZ by the KEM is the best when compared to the predictions of the other two-equation models. On the other hand, the size of the CTRZ is much better predicted by the stress closures in comparison with the experimental values.

\subsubsection{Turbulence Quantities}

The measured and predicted turbulence intensities and Reynolds shear stresses for the strongly swirling flow are shown in Fig. (9a-d). Comparing the measured values of the three turbulence intensity components in Fig. $(\mathbf{9 a}, \mathbf{b})$, it can easily be seen that the flow is anisotropic. Normal stresses reveal one peak at $r / H \approx 1.5$ as shown in the near-field regions of Fig. $(\mathbf{9 a}, \mathbf{b})$. Turbulence activities decrease in the mid- and far-field. The peak value of axial normal stresses moves toward the wall as it decays in strength and grows in size, indicating a progressive development of the jet flow [67].
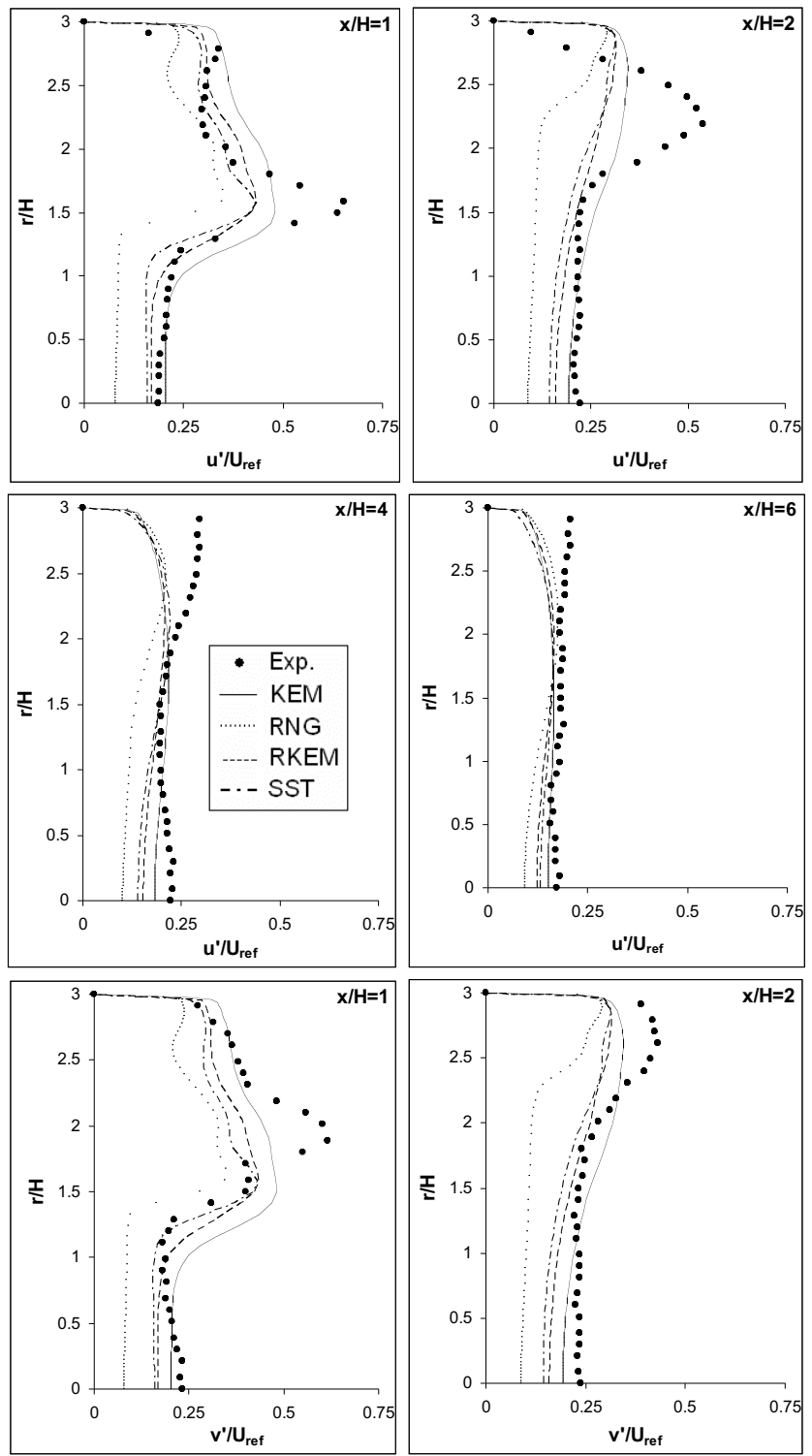
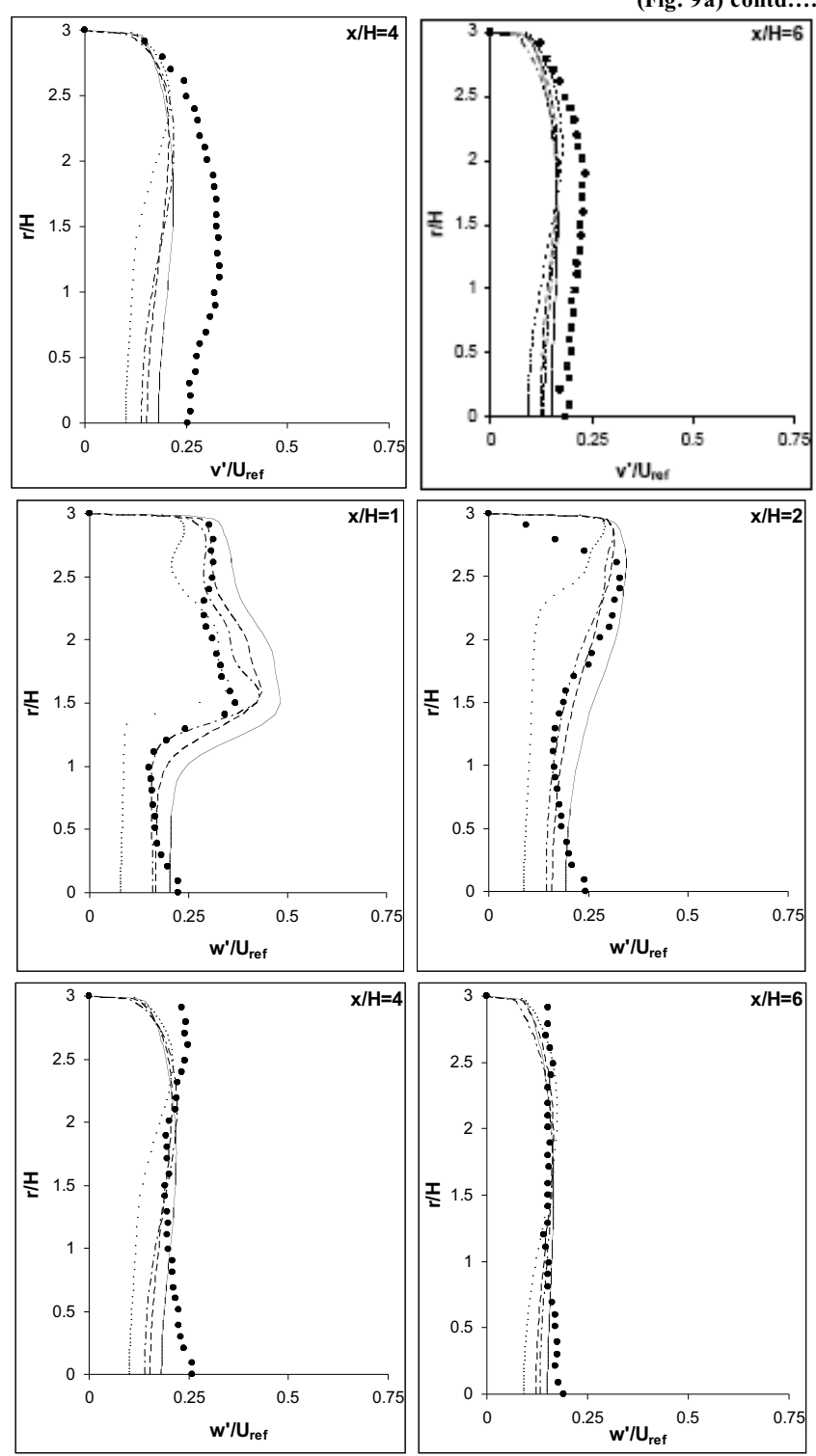

Fig. (9a). Radial profiles of normalized turbulence intensities $(S=0.81)$; Eddy-viscosity models.

In the near-field, the $R N G$ shows the worst results in the prediction of the axial turbulence intensity, while the performance of the other eddy-viscosity models is satisfactory, though still less accurate when compared to the predictions of the stress closures. The peak values of the normal stresses in the mid-field occur near the walls where most of the flow is located. In the mid-field, again the $R N G$ shows very poor results in predicting $u^{\prime}$. The performance of the KEM is comparable to those of the $R S M$ and the $S S G$. In the far- and very far-field regions, turbulence activity is weak except for the reverse flow regions near the centerline. In the experimental paper [67], it is mentioned, and not shown, that in the very far-field, $x / H>6$, the peaks occur at the centerline since the mixing near the wall disappears and the reverse flow is located only near the centerline. All the employed models underpredict the values of the turbulence intensities near the 
centerline in the far-filed; however the $S S G$ shows more accurate results in this region.

The features of the radial and tangential turbulent normal stresses are similar to those of the axial normal stresses, except in the mid-field of $v^{\prime}$ where the peak occurs at $r / H \approx 1.5$. The $R N G$ shows the worst results in the prediction of these two components of the turbulence intensity, while the results of the other eddy-viscosity models are in fairly good agreement with the measured data. Similar to the predictions of the Reynolds stress closures for the axial turbulence intensity, the results of the $R S M$ and the $S S G$ for $v^{\prime}$ and $w^{\prime}$ are superior to those of the eddy-viscosity models.
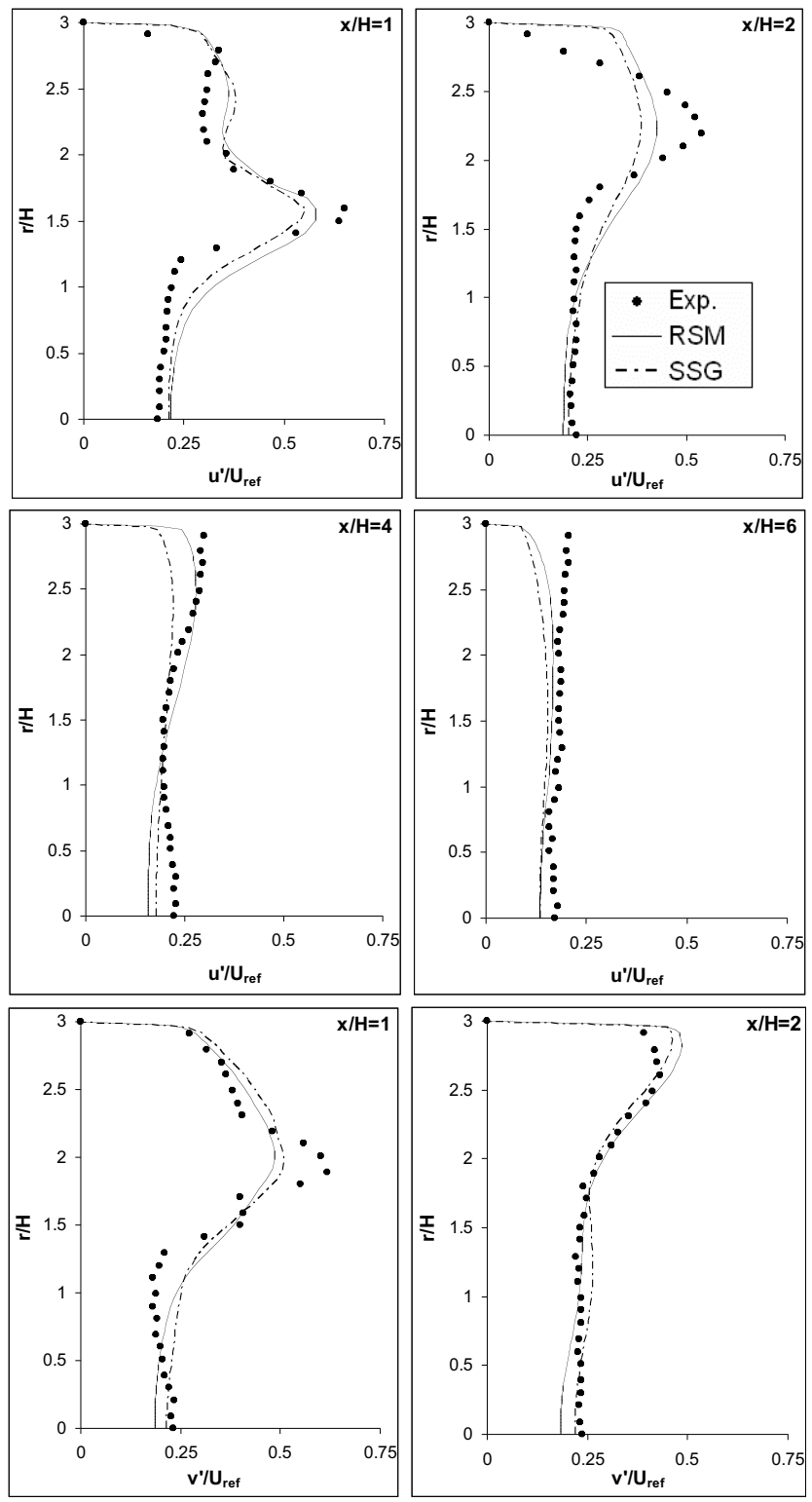

(Fig. 9b) contd.....
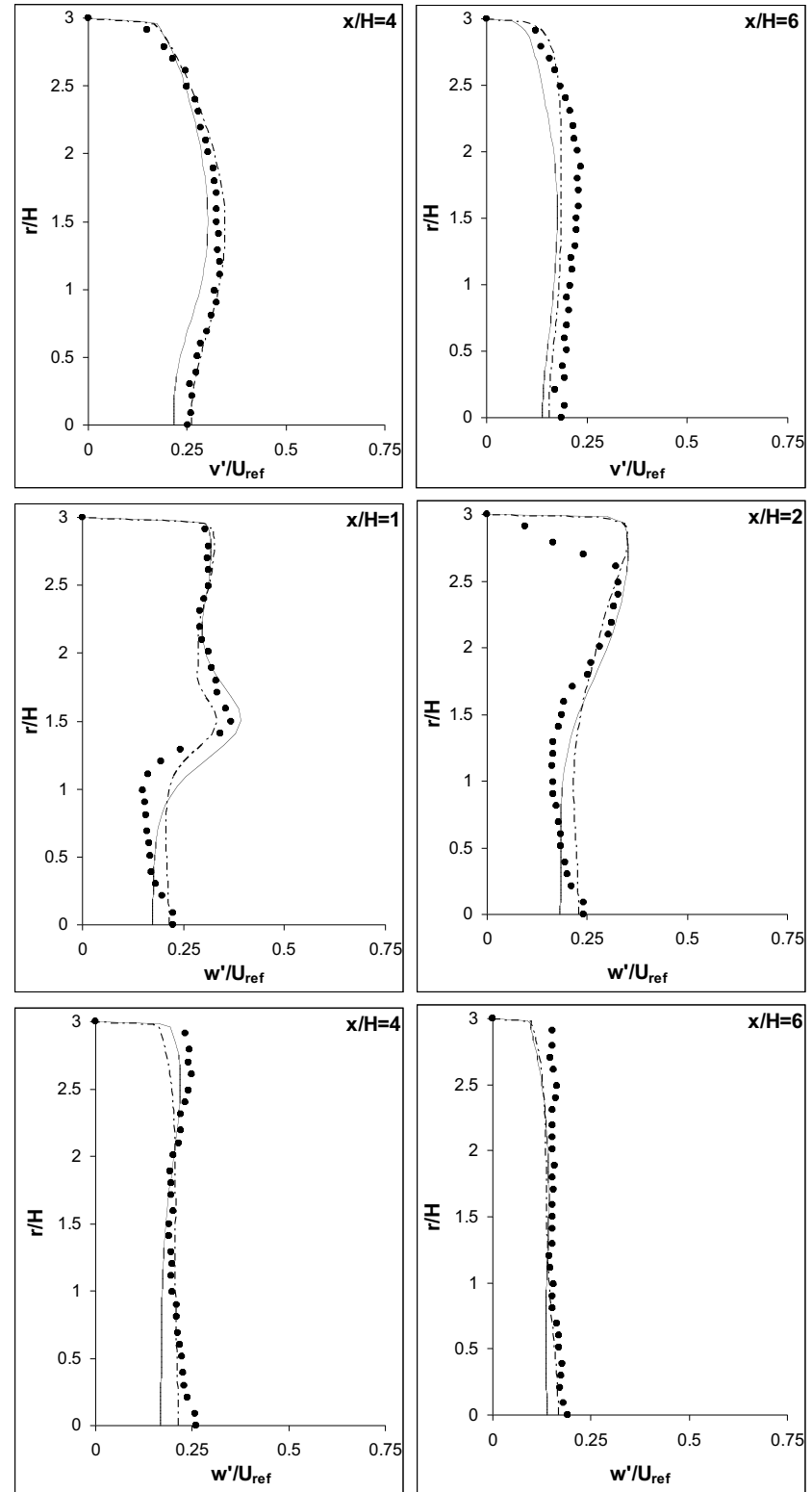

Fig. (9b). Radial profiles of normalized turbulence intensities $(S=0.81)$; Reynolds stress closures.

Profiles of the Reynolds shear stresses presented in Fig. $(9 c, d)$ show that the swirling jet flow is thin near the dump plane and then expands to fill the entire combustor in the farfield [67]. Since the magnitude of the Reynolds shear stresses in the mid- and far-field is small, the differences between the results obtained by using different models are not very large. In the near-field, the eddy-viscosity models do not depict the experimental trends of $\overline{u^{\prime} v^{\prime}}$. On the other hand, the stress closures show the same trends as those of the experiment with different magnitudes. 
In the prediction of the second Reynolds shear stress, $\overline{u^{\prime} w^{\prime}}$, all the models show fairly good results in the nearfield, except in the near-wall region. In the mid-field, none of the models are able to predict $\overline{u^{\prime} w^{\prime}}$ accurately.

In conclusion, among the eddy-viscosity models, the RKEM shows better predictions of the turbulence field. The numerical results based on the two Reynolds stress closures are all better than those obtained by the eddy-viscosity models, especially in the near-field region where the flow is highly anisotropic. However, even the RSM and the $S S G$ fail to reproduce accurate enough results in the near wall region at some axial locations (e.g. at $x / H=2$ ) and also, as mentioned before, near the centerline in the far-field.
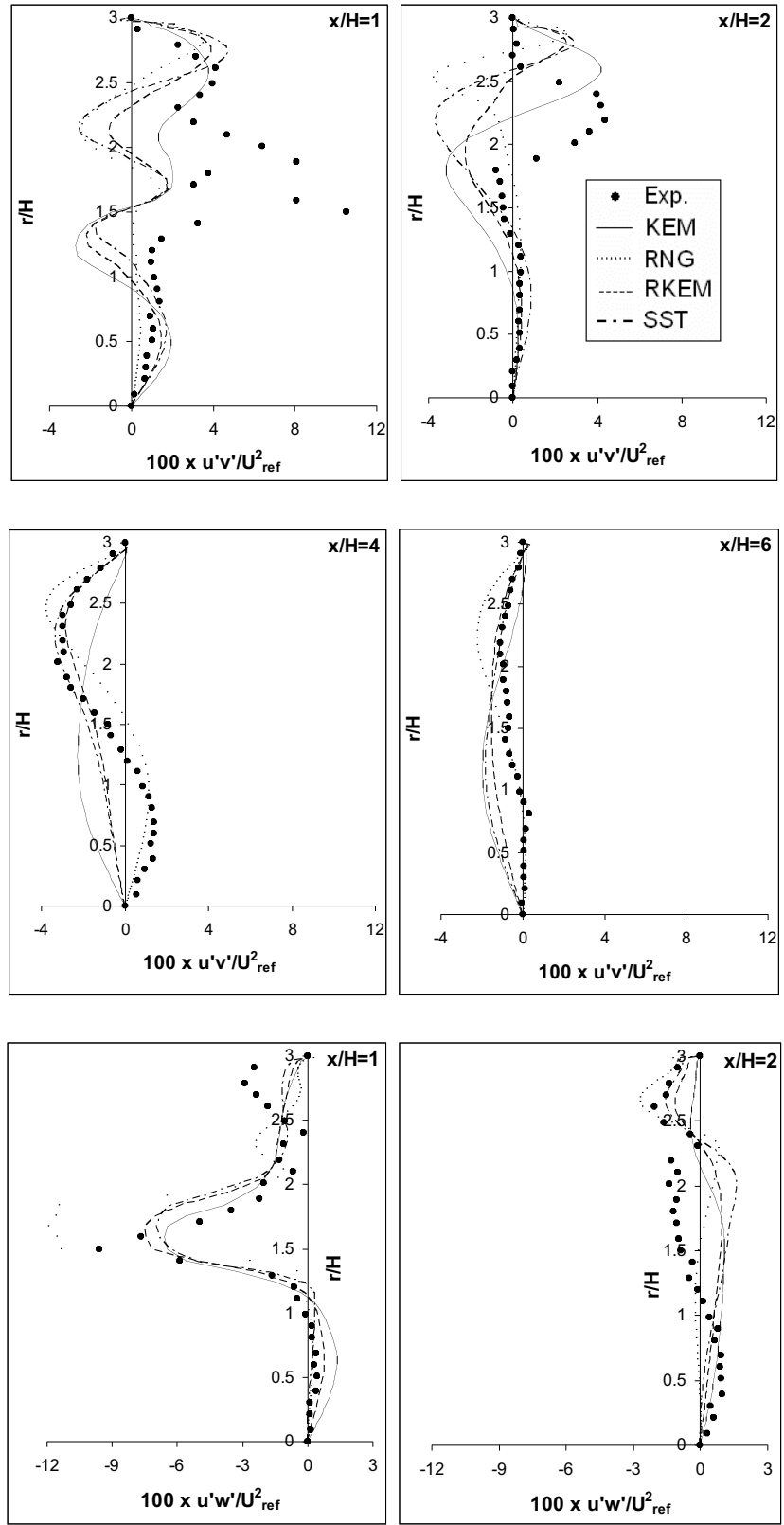

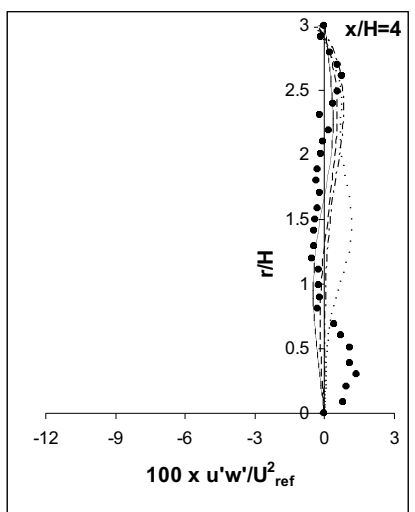

(Fig. 9c) contd.....

Fig. (9c). Radial profiles of normalized shear stresses $(S=0.81)$; Eddy-viscosity models
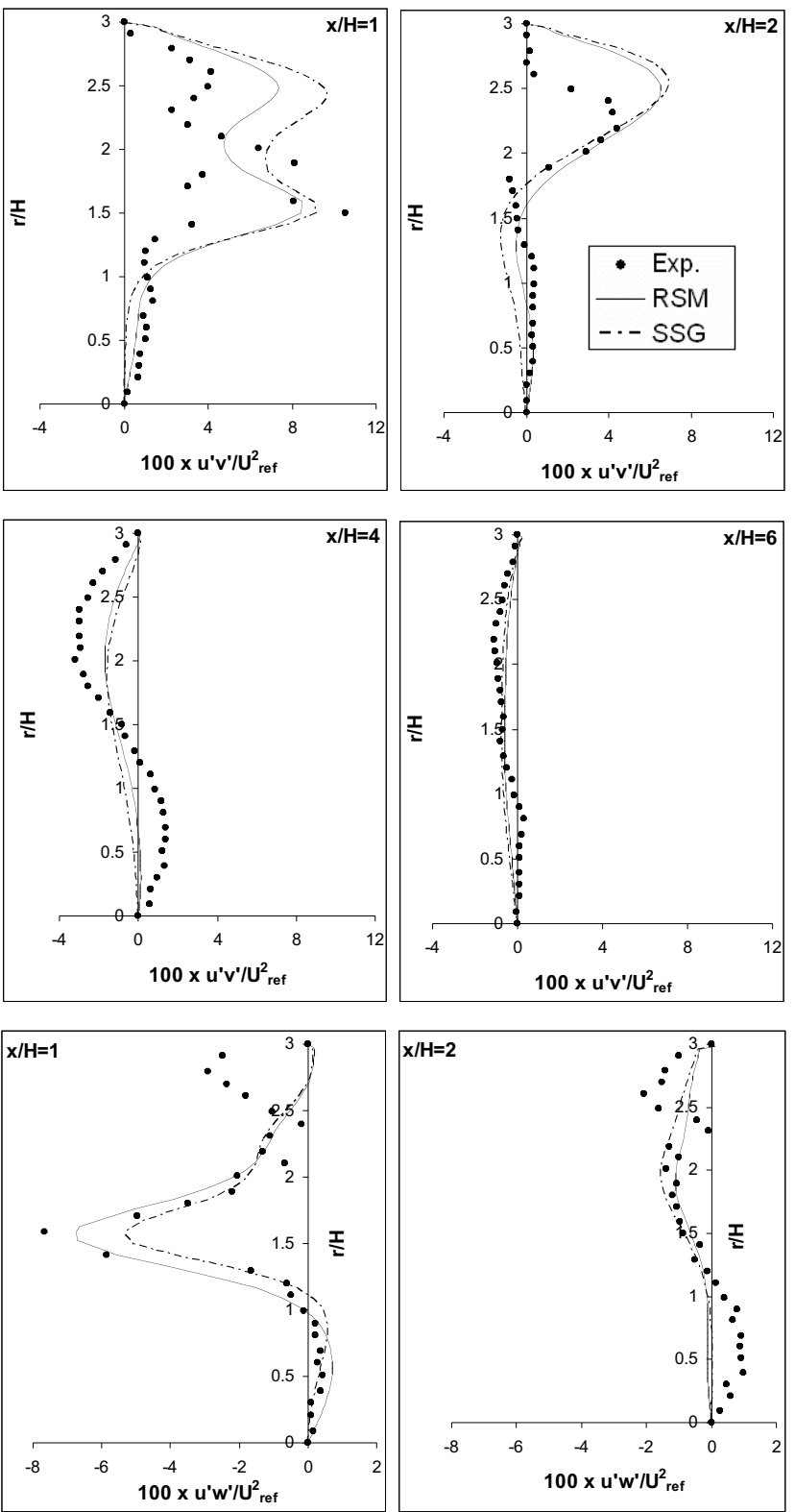
(Fig. 9d) contd.....

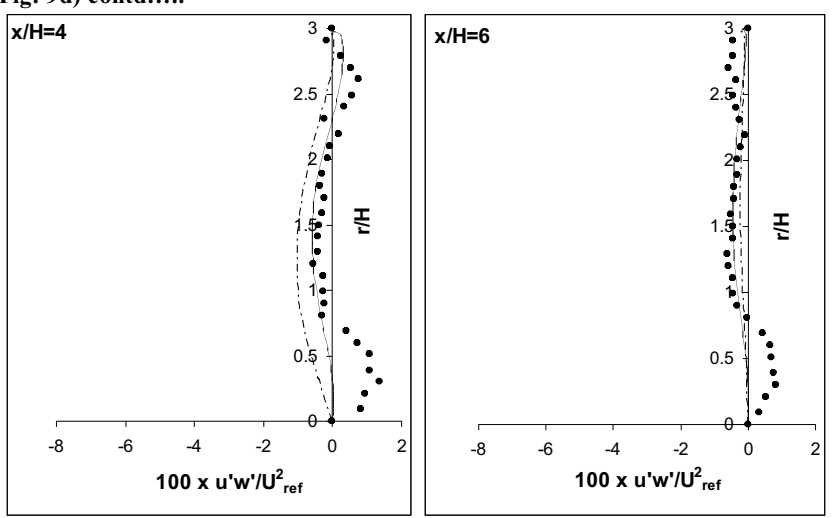

Fig. (9d). Radial profiles of normalized shear stresses $(S=0.81)$; Reynolds stress closures

\section{CONCLUSIONS}

Simulation of turbulent swirling flows in axisymmetric sudden expansion combustor has been performed for two different inlet swirl numbers (i.e. $S=0.4$ and $S=0.81$ ) in the same combustor geometry. The main conclusions are summarized below.

- In comparison with all the tested models, the standard $R S M$ and the $S S G$ produce the best predictions of the mean velocity profiles. The performance of the eddyviscosity models in predicting the mean velocities is competetive. At low swirl numbers, both the RSM and the $S S G$ predict reasonably accurate mean velocity profiles in comparison with their experimental counterparts. At high swirl numbers, however, these two models underpredict the profiles of the tangential mean velocity especially in the inner flow region.

- $\quad$ The CRZ in both flow configurations is predicted by all the tested models. Swirl intensity effect is significant in reducing the size of CRZ from four step heights, for $S=0.4$, to less than two-step heights, for $S=0.81$. It is found that all the employed turbulence models could predict the effect of swirl intensity on the axial location of the corner flow reattachment point. In the flow configuration with low swirl number, the predicted size of the CRZ by the KEM is the best in comparison with the experimental value. In the flow configuration with high swirl numbers, $S=0.81$, the predicted size of the corner reverse flow region by all the models is in good agreement with the experimental data.

- $\quad$ It is found that all the models can predict the CTRZ in the strongly swirling flow, although with different sizes. But, in the weakly swirling flow, only the RSM and the $S S G$ could predict the existence of the CTRZ in the flow field. In the weakly swirling flow, the predicted length (in the axial direction) of the CTRZ by the $R S M$ and the $S S G$ are around 40 percent shorter than that found experimentally, while they are 1.25 and 1.5 times wider (in the radial direction) than the measured width of the CTRZ. In the strongly swirling flow, it is found that both the RSM and the SSG pre- dict reasonably accurate size of the CTRZ in comparison with the experimental value.

- Numerical predictions of the stress closures for the turbulence quantities are much more accurate than those obtained by using the eddy-viscosity models, especially in the near-field region where the flow is anisotropic. However, even the RSM and the $S S G$ are inadequate for predicting the magnitude of the shear stresses especially in the mid-field whereas their trends are well captured. In the weakly swirling flow, among the eddy-viscosity models, the RKEM shows the most accurate predictions of the turbulence intensity components, while more accurate results of the Reynolds shear stresses can be obtained by employing the $K E M$. In the strongly swirling flow, the $R K E M$ shows the best predictions of the turbulence quantities among the eddy-viscosity models.

In summary, among the tested RANS turbulence models, the $S S G$ model shows the most accurate results in predicting the main characteristics of swirling flow in a can-combustor. However, its major handicap resides in its inability to capture accurate enough the flow characteristics near the centreline at high swirl intensities, as well as the magnitude of the Reynolds shear stresses in the near- and mid-field flow regions.

\section{ACKNOWLEDGEMENTS}

The financial support for this research is provided by Manitoba Hydro Research and Development Department.

\section{NOMENCLATURE}

\begin{tabular}{|c|c|}
\hline$b_{i j}$ & $=$ Reynolds stress anisotropic tensor \\
\hline$C_{1}, C_{2}$ & $=$ Reynolds stress models constants \\
\hline$C_{3}, C_{4}, C_{5}=$ & $=S S G$ model constants \\
\hline$C_{1}^{*}, C_{3}^{*}$ & $=S S G$ model constants \\
\hline$C_{1}^{\prime}, C_{2}^{\prime}$ & $=$ Standard Reynolds stress model constants \\
\hline$C_{1 \varepsilon}, C_{2 \varepsilon}, C_{\mu}=$ & $\begin{aligned} l= & k-\varepsilon \text { Based models constants and Reynolds } \\
& \text { stress models constants }\end{aligned}$ \\
\hline$D$ & $=$ Diameter of the combustor \\
\hline$D_{i j}$ & $\begin{aligned}= & \text { Diffusion term of Reynolds stress transport } \\
& \text { equation }\end{aligned}$ \\
\hline$H$ & $=$ Step height \\
\hline$k$ & $=$ Turbulent kinetic energy \\
\hline$=$ & $=$ Turbulence length scale \\
\hline$P$ & $=$ Pressure \\
\hline$P_{i j}$ & $\begin{aligned}= & \text { Production term of Reynolds stress transport } \\
& \text { equation }\end{aligned}$ \\
\hline$=$ & $=$ Swirl number \\
\hline$S_{i j}$ & $=$ Mean rate of strain tensor \\
\hline$u_{i}, u_{j}, u_{k}$ & $=$ Velocity fluctuation components \\
\hline & $=$ Reynolds stresses \\
\hline
\end{tabular}




$$
\begin{array}{ll}
U_{i}, U_{j}, U_{k} & =\text { Mean velocity components } \\
x & =\text { Axial distance to the dump plane } \\
x_{i}, x_{j}, x_{k} & =\text { Space directions }
\end{array}
$$

\section{Greek Letters}

$$
\begin{array}{lll}
\Omega_{i j} & = & \text { Mean vorticity tensor } \\
\delta_{i j} & = & \text { Kronecker operator } \\
\varepsilon & = & \text { Rate of dissipation of } k \\
\varepsilon_{i j} & = & \begin{array}{l}
\text { Dissipation term of Reynolds stress transport } \\
\text { equation }
\end{array} \\
\Phi_{i j} & = & \text { Pressure strain term of Reynolds stress } \\
& \text { transport equation } \\
\mu & = & \text { Dynamic viscosity } \\
\mu_{t} & = & \text { Eddy viscosity } \\
\rho & = & \text { Density } \\
\sigma_{k}, \sigma_{\varepsilon} & = & k-\varepsilon \text { Based models constants and Reynolds } \\
v & \text { stress models constants } \\
\omega & = & \text { Kinematic viscosity } \\
& = & \text { Specific dissipation Rate }
\end{array}
$$

\section{REFERENCES}

[1] B.E. Launder, and D.B. Spalding, "Lectures in Mathematical Models of Turbulence”, London, UK. Academic Press, 1972.

[2] W.P. Jones, and B.E. Launder, "The prediction of laminarization with a two-equation model of turbulence", Int. J. Heat Mass Trans., Vol. 15(2), pp. 301-314, 1972.

[3] C.G. Speziale, "On nonlinear $k-l$ and $k-\varepsilon$ models of turbulence", $J$. Fluid Mech., Vol. 178, pp. 459-475, 1987.

[4] K.Y. Chien, "Prediction of channel and boundary layer flows with a low-Reynolds-number turbulence model", AIAA J., Vol. 20(1), pp. 33-38, 1982.

[5] W. Rodi, "Recent developments in turbulence modeling", in Iwasa, Y., Tamai, N. and Wada, A. (Eds.): Proc. of the $3^{\text {rd }}$ Int. Symposium on Refined Flow Modeling and Turbulence Measurements, Tokyo, Japan. 1988.

[6] S. Hogg, and M.A. Leschziner, "Computation of highly swirling confined flow with a Reynolds stress turbulence model", AIAA J., Vol. 27(1), pp. 57-63, 1989.

[7] W.P. Jones, and A. Pascau, "Calculation of confined swirling flows with a second moment closure", J. Fluids Eng., Vol. 111(3), pp. 248-255, 1989.

[8] M.A.R. Sharif, and Y.K.E. Wong, "Evaluation of the performance of three turbulence closure models in the prediction of confined swirling flows", Comput. Fluids, Vol. 24(1), pp. 81-100, 1995.

[9] J.C. Chen, and C.A. Lin, "Computations of strongly swirling flows with second-moment closures", Int. J. Numer. Methods Fluids, Vol. 30(5), pp. 493-508, 1999.

[10] M.I. Yaras, and A.D. Grosvenor, "Evaluation of one- and twoequation low-Re turbulence models. Part I-Axisymmetric separating and swirling flows", Int. J. Numer. Methods Fluids, Vol. 42(12), pp.1293-1319, 2003.

[11] X. Yang, and H. Ma, "Computation of strongly swirling confined flows with cubic eddy-viscosity turbulence models", Int. J. Numer. Methods Fluids, Vol. 43(12), pp. 1355-1370, 2003.

[12] A.S. Nejad, S.P. Vanka, S.C. Favaloro, M. Samimy, and C. Langenfeld, "Application of laser velocimetry for characterization of confined swirling flow", J. Eng. Gas Turb. Power, Vol. 111(1), pp.36-45, 1989.

[13] R. Weber, B.M. Visser, and F. Boysan, "Assessment of turbulence modeling for engineering prediction of swirling vortices in the near burner zone", Int. J. Heat Fluid Flow, Vol. 11(3), pp. 225-235, 1990.

[14] S.C. Favaloro, A.S. Nejad, and S.A. Ahmed, "Experimental and computational investigation of isothermal swirling flow in an axi- symmetric dump combustor", J. Propul. Power, Vol. 7(3), pp. 348356, 1991.

[15] J.J. McGuirkand, J.M.L.M. Palma, "The flow inside a model gas turbine combustor: Calculations", J. Eng. Gas Turb. Power, Vol. 115(3), pp. 594-602, 1993

[16] J. Zhu, and T.H. Shih, "Computation of confined coflow jets with three turbulence models", Int. J. Numer. Methods Fluids, Vol. 19(10), pp. 939-956, 1994

[17] C.A. Lin, and C.M. Lu, "Modeling three-dimensional gas-turbine combustor model flow using second-moment closure", AIAA J., Vol. 32(7), pp. 1416-1422, 1994.

[18] J.H. Tsai, C.A. Lin, and C.M. Lu, "Modeling dump combustor flows with and without swirl at the inlet using Reynolds stress models", Int. J. Numer. Method Heat Fluid Flow, Vol. 5(7), pp. 577-588, 1995.

[19] J.L. Xia, G. Yadigaroglu, Y.S. Liu, J. Schmidli, and B.L. Smith, "Numerical and experimental study of swirling flow in a model combustor", Int. J. Heat Mass Trans., Vol. 41(11), pp.1485-1497, 1998.

[20] Y. Lei, J. Zhang, and L. Zhou, "Simulation of swirling turbulent flows of coaxial jets in a combustor", Numer. Heat Trans. A Appl., Vol. 37(2), pp. 189-199, 2000.

[21] U. Engdar, and J. Klingmann, "Investigation of two-equation turbulence models applied to a confined axis-symmetric swirling flow", ASME-PVP, Vol. 448(2), pp. 199-206, 2002.

[22] P. Flohr, P. Schmitt, and C.O. Paschereit, "Mixing field analysis of a gas turbine burner", ASME-FACT, New Orleans, LA, US, pp. 45-53, 2002

[23] S. Jakirlic, K. Hanjalic, and C. Tropea, "Modeling rotating and swirling turbulent flows: A perpetual challenge", AIAA J., Vol. 40(10), pp.1984-1996, 2002.

[24] X. Wei, J. Zhang, and L. Zhou, "A new algebraic mass flux model for simulating turbulent mixing in swirling flow", Numer. Heat Trans. B-Fund., Vol. 45(3), pp.283-300, 2004.

[25] J. Zhang, Y. Lei, and L. Zhou, "Simulation of coaxial jet interactions in a swirl combustor", Combust. Sci. Technol., Vol. 176(1), pp. 23-43, 2004.

[26] Y.N. Huang, H.Y. Ma, and H.J. Chu, "Modeling turbulent swirling flows based on the algebraic two-equation $(k-\varepsilon)$ approach", Int. J. Numer. Methods Fluids, Vol. 51(3), pp. 285-304, 2006.

[27] P. Habisreuther, C. Bender, O. Petsch, H. Buchner, and H. Bockhorn, "Prediction of pressure oscillations in a premixed swirl combustor flow and comparison to measurements", Flow Turbul. Combust., Vol. 77(1-4), pp. 147-160, 2006.

[28] J.M. Tsao, and C.A. Lin, "Reynolds stress modelling of jet and swirl interaction inside a gas turbine combustor", Int. J. Numer. Methods Fluids, Vol. 29(4), pp. 451-464, 1999.

[29] R.M. So, S.A. Ahmed, and H.C. Mongia, "An experimental investigation of gas jets in confined swirling air flow", NASA CR 3832 , 1984.

[30] P. Bradshaw, B.E. Launder, and J.L. Lumley, "Collaborative testing of turbulence models", J. Fluids Eng., Vol. 118(2), pp. 243247, 1996.

[31] B.E. Launder, C.H. Priddin, and B.I. Sharma, "The calculation of turbulent boundary layers on spinning and curved surfaces", J. Fluids Eng., Vol. 99(1), pp. 231-239, 1977.

[32] C.P. Chen, "Multiple-scale turbulence model in confined swirling jet predictions", AIAA J., Vol. 24(10), pp. 1717-1719, 1986.

[33] L.D. Smoot, and P.J. Smith, Coal Combustion and Gasification, NewYork, USA: Plenum Press, 1985.

[34] C.C. Hwang, G. Zhu, M. Massoudi, and J.M. Ekmann, "Comparison of the linear and the nonlinear k- $\varepsilon$ turbulence models in combustors”, J. Fluids Eng., Vol. 115(1), pp. 93-102, 1993.

[35] O. Kitoh, "Experimental study of turbulent swirling flow in a straight pipe", J. Fluid Mech., Vol. 225, pp. 445-479, 1991.

[36] V. Yakhot, S.A. Orszag, S. Thangam, T.B. Gatski, and C.G. Speziale, "Development of turbulence model for shear flows by a double expansion technique", Phys. Fluids A-Fluid, Vol. 4(7), pp 1510-1520, 1992.

[37] S.A. Orszag, V. Yakhot, W.S. Flannery, F. Boysan, D. Choudhury, J. Maruszewski, and B. Patel, "Renormalization group modeling and turbulence simulations", Proc. of the Int. Conference on NearWall Turbulent Flows, Tempe, AZ, USA, pp. 1031-1046, 1993.

[38] G.C. Papageorgakis, and D.N. Assanis, "Comparison of linear and nonlinear $R N G$-based $k-\varepsilon$ models for incompressible turbulent flows", Numer. Heat Trans. B-Fund., Vol. 35(1), pp. 1-22, 1999. 
[39] K. Hanjalic, "Advanced turbulence closure models: A view of current status and future prospects", Int. J. Heat Fluid Flow, Vol. 15(3), pp.178-203, 1994.

[40] T.H. Shih, W.W. Liou, A. Shabbir, Z. Yang, and J. Zhu, "A new $k$ $\varepsilon$ eddy-viscosity model for high Reynolds number turbulent flows", Comput. Fluids, Vol. 24(3), pp. 227-238, 1995.

[41] FLUENT User's Guide, Fluent Inc., Lebanon NH 03766, USA, 2005.

[42] F.R. Menter, "Two-equation eddy-viscosity turbulence models for engineering applications", AIAA J., Vol. 32(8), pp. 1598-1605, 1994.

[43] Boysan, F. and J. Swithenbank, "Numerical prediction of confined vortex flows", Proc. of the $2^{\text {nd }}$ Int. Conference on Numerical Methods in Laminar and Turbulent Flow, Venice, Italy, pp. 425-437, 1981.

[44] S. Fu, P.G. Huang, B.E. Launder, and M.A. Leschziner, "A comparison of algebraic and differential second-moment closures for axisymmetric turbulent shear flows with and without swirl", J. Fluids Eng., Vol. 110(2), pp. 216-221, 1988.

[45] J. Zhang, S. Nieh, and L. Zhou, "A new version of algebraic stress model for simulating strongly swirling turbulent flows", Numer. Heat Trans. B-Fund., Vol. 22(1), pp. 49-62, 1992.

[46] J. Zhang, H. Lu, L. Zhou, and S. Nieh, "Simulation of annular swirling turbulent flows with a new algebraic Reynolds stress model", Numer. Heat Trans. B-Fund., Vol. 31(2), pp. 235-249, 1997.

[47] B.E. Launder, G.J. Reece, and W. Rodi, "Progress in the development of a Reynolds-stress turbulence closure", J. Fluid Mech., Vol. 68, pp. 537-566, 1975.

[48] S. Hogg, and M.A. Leschziner, "Second moment closure calculation of strongly swirling confined flow with large density gradients", Int. J. Heat Fluid Flow, Vol. 10(1), pp. 16-27, 1989

[49] M. Ohtsuka, "Numerical analysis of swirling non-reacting and reacting flows by the Reynolds stress differential method", Int. J. Heat Mass Tran., Vol. 38(2), pp. 331-337, 1995.

[50] P. Lu, and V. Semiao, "A new second-moment closure approach for turbulent swirling confined flows", Int. J. Numer. Methods Fluids, Vol. 41(2), pp. 133-150, 2003.

[51] L.N. Jones, P.H. Gaskeli, H.M. Thompson, X.J. Gu, and D.R. Emerson, "Anisotropic, isothermal, turbulent swirling flow in a complex combustor geometry", Int. J. Numer. Methods Fluids, Vol. 47(10-11), pp. 1053-1059, 2005.

[52] A.M. Jawarneh, and G.H. Vatistas, "Reynolds stress model in the prediction of confined turbulent swirling flows", J. Fluids Eng., Vol. 128(6), pp. 1377-1382, 2006.

[53] R. Palm, S. Grundmann, M. Weismuller, S. Saric, S. Jakirlic, and C. Tropea, "Experimental characterization and modelling of inflow conditions for a gas turbine swirl combustor", Int. J. Heat Fluid Flow, Vol. 27(5), pp. 924-936, 2006.

[54] B.E. Launder, and A. Morse, "Numerical prediction of axisymmetric free shear flows with a Reynolds stress turbulence closure", in Bradbury, L.J.S., Durst, F., Launder, B.E., Schmidt, F.W. and Whitelaw, J.H. (Eds.): Turbulent Shear Flows, Vol. 1, pp. 279-294, 1979.

[55] F.C. Lockwood, and B. Shen, "Performance predictions of pulverized-coal flames of power station furnace and cement kiln types", P. Combust. Inst., Vol. 25, pp. 503-509, 1994.

[56] P. Lu, T. Ye, M. Costa, V. Semiao, and M.G. Carvalho, "Prediction with a second moment closure turbulence model and experiments of combined combustion of pulverized coal and propane in a semiindustrial combustor", Proc. of the $4^{\text {th }}$ Int. Symposium on Coal Combustion, Beijing, China, pp. 356-367, 1999.

[57] K. Hanjalic, "Second-moment turbulence closure for CFD: Need and prospects", Int. J. Comput. Fluid D., Vol. 12, pp. 67-97, 1999.

[58] J.L. Lumley, and B.J. Khajeh-Nouri, "Computational modelling of turbulent transport", Adv. Geophys., Vol. 18A, pp. 169-192, 1974.

[59] C.G. Speziale, S. Sarkar, and T.B. Gatski, "Modelling the pressurestrain correlation of turbulence: An invariant dynamical systems approach", J. Fluid Mech., Vol. 227, pp. 245-272, 1991.
[60] B. Basara, and B.A. Younis, "Assessment of the SSG pressurestrain model in two-dimensional turbulent separated flows", Appl. Sci. Res., Vol. 55(1), pp. 39-61, 1995.

[61] B.A. Younis, T.B. Gatski, and C.G. Speziale, "Assessment of the SSG pressure-strain model in free turbulent jets with and without swirl”, J. Fluids Eng., Vol. 118(4), pp. 800-809, 1996.

[62] S.A. Ahmed, and A.S. Nejad, "Swirl effects on confined flows in axisymmetric geometries", J. Propul. Power, Vol. 8(2), pp. 339345, 1992.

[63] S.A. Ahmed, and A.S. Nejad, "Velocity measurements in a research combustor - Part1. Isothermal swirling flow", Exp. Therm. Fluid Sci., Vol. 5(2), pp. 162-174, 1992.

[64] M.A. Habib, and J.H. Whitelaw, "Velocity characteristics of confined coaxial jets with and without swirl", J. Fluids Eng., Vol. 102(1), pp. 47-53, 1980.

[65] G. Baoyu, T.A.G. Langrish, and D.F. Fletcher, "Simulation of turbulent swirl flow in an axisymmetric sudden expansion", AIAA J., Vol. 39(1), pp. 96-102, 2001.

[66] P. Wang, X.S. Bai, M. Wessman, and J. Klingmann, "Large eddy simulation and experimental studies of a confined turbulent swirling flow", Phys. Fluids, Vol. 16(9), pp. 3306-3324, 2004.

[67] S.A. Ahmed, A.Z. Al-Garni, and K.B. Abidogun, "The flowfield characteristics of a confined highly swirling turbulent flow", Can. Aeronaut. Space J., Vol. 45(4), pp. 323-334, 1999.

[68] B.E. Launder, and D.B. Spalding, "The numerical computation of turbulent flows", Comput. Method. Appl. M., Vol. 3(2), pp. 269289, 1974.

[69] V. Yakhot, and S.A. Orszag, "Renormalization group analysis of turbulence: I. Basic theory", J. Sci. Comput., Vol. 1(1), pp. 3-51, 1986.

[70] D. Choudhury, "Introduction to the renormalization group method and turbulence modeling", Fluent Inc. Technical Memorandum TM-107, Lebanon NH 03766, USA, 1993.

[71] F.R. Menter, M. Kuntz, and R. Langtry, "Ten years of industrial experience with the SST turbulence model", $4^{\text {th }}$ International Symposium on Turbulence, Heat and Mass Transfer, pp. 625-632, 2003.

[72] B.J. Daly, and F.H. Harlow, "Transport equations in turbulence", Phys. Fluids, Vol. 13(11), pp. 2634-2649, 1970

[73] F.S. Lien, and M.A. Leschziner, "Assessment of turbulent transport models including non-linear RNG eddy-viscosity formulation and second-moment closure for flow over a backward-facing step", Comput. Fluids, Vol. 23(8), pp. 983-1004, 1994.

[74] M.M. Gibson, and B.E. Launder, "Ground effects on pressure fluctuations in the atmospheric boundary layer", J. Fluid Mech., Vol. 86, pp. 491-511, 1978

[75] S. Fu, B.E. Launder, and M.A. Leschziner, "Modeling strongly swirling recirculating jet flow with Reynolds-stress transport closures", Proc. of the $6^{\text {th }}$ Symposium on Turbulent Shear Flows, Toulouse, France, pp. 17.6.1-17.6.6, 1987.

[76] B.E. Launder, "Second-moment closure and its use in modeling turbulent industrial flows", Int. J. Numer. Methods Fluids, Vol. 9(8), pp. 963-985, 1989

[77] B.E. Launder, "Second-moment closure: Present and future?", Int. J. Heat Fluid Flow, Vol. 10(4), pp. 282-300, 1989.

[78] S.E. Kim, and D. Choudhury, "Near-wall treatment using wall functions sensitized to pressure gradient", ASME-FED, Separated Complex Flows, Vol. 217, pp. 273-280, 1995.

[79] R.I. Issa, "Solution of the implicitly discretized fluid flow equations by operator-splitting", J. Comput. Phys., Vol. 62(1), pp. 40$65,1986$.

[80] B.P. Leonard, "A stable and accurate convective modeling procedure based on quadratic upstream interpolation", Comput. Methods Appl. M., Vol. 19(1), pp. 59-98, 1979.

[81] C.A. Lin, and J.H. Tsai, "Computations of strongly swirling flows with second-moment closures", $16^{\text {th }}$ National Conference on Theoretical and Appl Mechanics, Keelung, Taiwan, pp. 127-134, 1992. 